NBER WORKING PAPER SERIES

\title{
BEYOND HEALTH: NON-HEALTH RISK AND THE VALUE OF DISABILITY INSURANCE
}

\author{
Manasi Deshpande \\ Lee Lockwood
}

Working Paper 28852

http://www.nber.org/papers/w28852

\author{
NATIONAL BUREAU OF ECONOMIC RESEARCH \\ 1050 Massachusetts Avenue \\ Cambridge, MA 02138 \\ May 2021
}

Deshpande conducted this research as a Visiting Economist at the Social Security Administration (SSA). We thank the Office of Research, Evaluation, and Statistics at SSA for providing access to administrative data, and Katherine Bent, Ben Danforth, Jeffrey Hemmeter, Steve Robinson, Mark Sarney, Alexander Strand, Robert Weathers, and several SSA components for feedback. We are grateful to David Autor, Katherine Baicker, Julie Berry Cullen, Joseph Doyle, Arindrajit Dube, Mark Duggan, Liran Einav, Amy Finkelstein, Leora Friedberg, Michael Greenstone, Steven Haider, Jill Horwitz, William Johnson, Henrik Kleven, Jonathan Kolstad, Magne Mogstad, Timothy Moore, Austin Nichols, Matthew Notowidigdo, Edgar Olsen, Luigi Pistaferri, James Poterba, Adam Sacarny, Joseph Shapiro, Isaac Sorkin, Stefanie Stantcheva, Melanie Wasserman, and seminar participants at Federal Reserve Board, Michigan State, MIT, Stanford, IllinoisChicago, and Wisconsin-Madison for helpful comments. We thank Yalun Su and Jiada Ye for excellent research assistance. Deshpande thanks the Ronzetti Initiative for the Study of Labor Markets at the Becker-Friedman Institute for financial support. This material is based upon work supported by the National Science Foundation under Grant No. 1941538. The views expressed herein are those of the authors and do not necessarily reflect the views of the National Bureau of Economic Research.

NBER working papers are circulated for discussion and comment purposes. They have not been peer-reviewed or been subject to the review by the NBER Board of Directors that accompanies official NBER publications.

(C) 2021 by Manasi Deshpande and Lee Lockwood. All rights reserved. Short sections of text, not to exceed two paragraphs, may be quoted without explicit permission provided that full credit, including $\odot$ notice, is given to the source. 
Beyond Health: Non-Health Risk and the Value of Disability Insurance

Manasi Deshpande and Lee Lockwood

NBER Working Paper No. 28852

May 2021

JEL No. H5,I3

\begin{abstract}
$\underline{\text { ABSTRACT }}$
The public debate over disability insurance has centered on concerns about individuals without severe health conditions receiving benefits. We go beyond health risk alone to quantify the overall insurance value of U.S. disability programs, including value from insuring non-health risk. We find that disability recipients, especially those with less-severe health conditions, are much more likely to have experienced a wide variety of non-health shocks than non-recipients. Selection into disability receipt on the basis of non-health shocks is so strong among individuals with less-severe health conditions that by many measures less-severe recipients are worse off than more-severe recipients. As a result, under baseline assumptions, benefits to less-severe recipients have an annual surplus value (insurance benefit less efficiency cost) over cost-equivalent tax cuts of $\$ 7,700$ per recipient, about three-fourths that of benefits to more-severe recipients $(\$ 9,900)$. Insurance against non-health risk accounts for about one-half of the value of U.S. disability programs.
\end{abstract}

\author{
Manasi Deshpande \\ Department of Economics \\ University of Chicago \\ 1126 E 59th St. \\ Chicago, IL 60637 \\ and NBER \\ mdeshpande@uchicago.edu \\ Lee Lockwood \\ Department of Economics \\ University of Virginia \\ Monroe Hall, Room 248 \\ 248 McCormick Rd \\ Charlottesville, VA 22903 \\ and NBER \\ leelockwood@virginia.edu
}

A data appendix is available at http://www.nber.org/data-appendix/w28852 


\section{Introduction}

Disability insurance is a major component of the social safety net in developed countries. In the United States, the Social Security Disability Insurance and Supplemental Security Income programs (which we collectively refer to as U.S. disability programs, or USDP) together provide access to health insurance and $\$ 200$ billion annually in cash benefits to nearly 13 million Americans. The main purpose of these programs is to provide assistance to people who cannot work because of severe health conditions. Yet the expansion of U.S. disability programs in recent decades has been attributed at least in part to non-health factors like stagnating wages (Autor and Duggan, 2003, 2006; Liebman, 2015), and there is widespread concern that providing benefits to individuals without severe health conditions is diluting the value of these programs. ${ }^{1}$

In this paper, we go beyond health risk alone to quantify the overall insurance value U.S. disability programs, including value from insuring non-health risk. We quantify the extent to which these programs insure different risks by comparing disability recipients and non-recipients along a wide variety of health and non-health dimensions, including consumption, adverse events like job loss, and resources available to cope with adverse events. Building on these comparisons, we make additional assumptions to quantify the (ex ante) value of receiving disability benefits in different states of the world: the net of the insurance benefit from receiving transfers in high-marginal utility states less the efficiency cost from distorting behavior. Reflecting the public debate over USDP, we focus on "mismatches with respect to health": individuals who receive benefits despite not having a health condition that exceeds a certain severity threshold ("less-severe recipients") and individuals who do not receive benefits despite having such a condition ("more-severe non-recipients"). ${ }^{2}$

Going "beyond health" is crucial for making informed judgments about disability programs and their mismatches with respect to health. Health, though likely a strong indicator of the value of receiving disability benefits, is not a perfect indicator because individuals face major non-health risks as well, including job loss, produc-

\footnotetext{
${ }^{1}$ More recently, growth in U.S. disability programs has slowed. Examples of concern include, "Unfit for Work: The startling rise of disability in America," Chana Joffe-Walt, NPR, March 23, 2013, and "How Americans Game the $\$ 200$ Billion-a-Year 'Disability-Industrial Complex,"' Avik Roy, Forbes, April 8, 2013.

${ }^{2}$ Such mismatches are not necessarily errors as defined by USDP rules, which explicitly account for certain non-health factors in eligibility determination (see Section 3 for details). We use "less/more-severe individual" as shorthand for "individual with a less-/more-severe health condition."
} 
tivity shocks, and changes in family structure. To the extent that a particular risk is not completely insured by other means, disability insurance potentially insures or exacerbates that risk, depending on selection into receiving disability benefits. For example, disability benefits in states of the world without a health shock but with limited earning prospects following job layoffs partially insure that risk. More generally, although mismatches with respect to health necessarily reduce the extent to which disability insurance insures health risk, the presence of non-health risk means that such mismatches might not reduce - and might even increase - the overall value of disability insurance. The extent to which mismatches insure non-health risk is therefore a critical determinant of the value of potential reforms. For example, unless benefits to less-severe recipients provide highly valuable insurance against non-health risk, reforms to limit such benefits, even at the expense of decreasing benefits to more-severe recipients, could produce large gains. But if benefits to less-severe recipients provide valuable insurance against non-health risk, such reforms could reduce the value of disability insurance. ${ }^{3}$

The extent to which disability programs and their mismatches with respect to health insure or exacerbate different risks is ultimately an empirical question, one that we investigate using complementary positive and normative analyses. In the positive analysis, we use a combination of survey and administrative data to establish new facts about the targeting of disability benefits on the basis of non-health factors. We find that less-severe disability recipients are on average much worse off than less-severe non-recipients, and by many non-health measures are even worse off than more-severe recipients. For example, we find in administrative data that prior to receiving disability benefits, less-severe recipients are $40 \%$ more likely to have experienced a mass layoff than more-severe recipients, $19 \%$ more likely to have experienced a foreclosure, and $23 \%$ more likely to have experienced an eviction. From survey data, less-severe recipients have similarly low consumption levels to more-severe recipients just prior to receiving disability benefits ( $\$ 17,000$ and $\$ 16,400$, respectively). Conversely, more-severe non-recipients are on average better off than either more-severe or less-severe recipients. The strong associations between disability receipt and non-

\footnotetext{
${ }^{3}$ Although it is natural to think that a risk would optimally be insured by "its own" program, that is not necessarily true when risks are richer than feasible policy instruments. For example, unemployment insurance typically does not insure any of the unemployment-related risk within unemployment spells of a given length, such as risk in re-employment wages or resources with which to smooth consumption during the spell.
} 
health shocks conditional on health means that USDP mismatches with respect to health are highly selected, in ways likely to increase the value of USDP, by both increasing insurance of non-health risk and decreasing distortion costs.

In the normative analysis, we determine how the targeting properties of U.S. disability programs, including their mismatches with respect to health, translate into their ex ante value, taking other programs as given. We use a flexible, sufficient statistics-type approach that highlights the importance, in a broad class of models, of two key factors in determining the value of disability benefits: the marginal utility of income and "counterfactual earnings" - earnings if not receiving disability benefits. We model marginal utility using PSID consumption measures and a wide range of assumptions about the functional form of utility. We model counterfactual earnings using quasi-experimental evidence from the literature on the effects of being awarded disability benefits. Our findings suggest that U.S. disability programs provide valuable insurance and increase welfare significantly. Under baseline assumptions, the value of disability benefits exceeds that of cost-equivalent tax cuts by $64 \%$, creating a surplus worth $\$ 8,700$ of government revenue per recipient per year. Moreover, we find that the high value of USDP is in part because of, not despite, mismatches with respect to health. We estimate that benefits to less-severe recipients create a value (insurance benefit less distortion cost) over cost-equivalent tax cuts of $\$ 7,700$ per recipient per year, about three-fourths that of benefits to more-severe recipients $(\$ 9,900)$. As a result, benefits to less-severe recipients do not decrease the value of USDP - they increase it considerably, accounting for about half of the total value. The lack of benefits to more-severe non-recipients also appears to create value, as providing such benefits would have a negative value $(-\$ 2,200$ per hypothetical recipient per year). USDP mismatches with respect to health are so favorably selected that U.S. disability programs are more valuable than a hypothetical, infeasible program that would target perfectly on severity. In other words, even somehow eliminating all mismatches at no administrative cost would significantly decrease the value of USDP. The estimates and conclusions are similar considering the cash benefits alone or the cash benefits combined with health insurance. Including health insurance modestly decreases the ratio of per-recipient surplus of benefits to less-severe relative to more-severe recipients, from 0.78 to $0.74-0.77$ depending on the exact specification.

The high values of U.S. disability programs and their mismatches with respect to health are driven by favorable selection on both marginal utility and counterfactual 
earnings. Much of the favorable selection into disability receipt is on the basis of nonhealth shocks. Using a decomposition analysis, we find that about one-half of the insurance value of USDP comes from insuring risk within observable health groups. This suggests that much, or even most, of the value of USDP comes from insuring non-health risk. USDP insurance of non-health risk in turn depends crucially on the strong selection into application, rather than on selective awards conditional on application. We estimate that a hypothetical disability program with similar adjudication standards but no systematic selection into application would have negative value, far below the large positive value of USDP. Although we lack direct evidence on what drives selection into application, additional simulation results suggest that earnings restrictions on recipients could play a key role.

We emphasize several points relevant for interpreting our results. First, our analysis, like most welfare analyses, takes other policies as given. That U.S. disability programs provide valuable insurance against a wide variety of risks may in part reflect gaps in the existing social safety net and does not imply that these programs are the most efficient way to insure these risks. Expanding other insurance programs like unemployment insurance or creating new programs like wage insurance or temporary disability insurance would potentially reduce the value of USDP, a point we revisit in Section 5.5. Second, our normative analysis focuses on insurance and welfare effects and does not explicitly incorporate non-welfarist considerations. ${ }^{4}$ Third, our results do not speak to the effects of changes to particular features of USDP, such as the earnings limit or the weight on health in the adjudication process, since such changes would induce application responses, evidence on which is sparse. Nor does our analysis speak to the alignment of U.S. disability programs with their program rules, since mismatches with respect to health are distinct from programmatic errors

\footnotetext{
${ }^{4}$ Such considerations might include the view that disability benefits should be received only by individuals with certain health conditions or the view that certain individuals are more deserving of benefits than others. Because quantitative evidence on the strength of such views is limited, rather than incorporate such considerations in our main analysis, we instead quantify how strong such considerations would have to be, in terms of their effects on generalized social marginal welfare weights (Saez and Stantcheva, 2016), in order to overturn our key conclusions. We find that a nonwelfarist planner who discounted the value of disability benefits to less-severe recipients (viewing each dollar of such benefits as being worth $\$(1-d)$, where $d$ is the discount) would get positive surplus from the actual disability benefits to less-severe recipients as long as the discount did not exceed about $35 \%(d=0.35)$. That same planner would get positive surplus from disability benefits as a whole as long as the discount on benefits to less-severe recipients did not exceed about $75 \%$ $(d=0.75)$.
} 
with respect to their rules, which include both health and non-health considerations. Fourth, the results do not imply that expanding disability receipt to new groups would increase social welfare - in fact, our analysis highlights that the value of USDP depends crucially on selective receipt. Finally, our normative analysis relies on several assumptions, including about behavioral responses to disability benefits, about which relatively little is known. Better understanding such behavioral responses and the benefits and costs of reforms to other policies is a high priority for future research.

Acknowledging these caveats, our results have implications for the current debate over disability programs. The most contentious question in the debate is whether benefits to individuals without more-severe health conditions are diluting the value of disability programs. Our results suggest that in the case of U.S. disability programs, such benefits are not diluting value but enhancing it. Whereas eliminating such benefits would significantly reduce the value of USDP, "doubling down" on them by increasing benefit levels - which, among other things, further increases transfers from more-severe non-recipients to less-severe recipients-would increase it.

The primary contribution of this paper is to quantify the extent to which U.S. disability programs and their mismatches with respect to health insure non-health as well as health risk and to determine the welfare implications of this insurance. Our findings help reconcile two seemingly contradictory strands of the literature on disability programs. The first is a positive, empirical strand that has raised serious concerns about disability programs. The key findings of this literature are that mismatches with respect to health are prevalent, negative labor market shocks increase disability enrollment, and disability programs reduce the labor supply of marginal recipients. ${ }^{5}$ These findings suggest that disability programs may provide benefits to many individuals without severe health conditions and that it discourages work. Our paper extends this literature by going "beyond health" to characterize more-severe and less-severe disability recipients and non-recipients on a wide variety of dimensions and to quantify the implications for the value of disability programs. The second, normative strand of literature on disability programs quantifies the welfare effects of various reforms. This strand typically finds that expanding disability programs would

\footnotetext{
${ }^{5}$ Mismatches: Benitez-Silva, Buchinsky and Rust (2004); Von Wachter, Song and Manchester (2011). Labor market shocks: Autor and Duggan (2003, 2006); Black, Daniel and Sanders (2002); Charles, Li and Stephens Jr (2018); Rege, Telle and Votruba (2009). Labor supply: Maestas, Mullen and Strand (2013); French and Song (2014).
} 
increase welfare. ${ }^{6}$ Our paper extends this literature by quantifying, with a flexible approach, the value of disability benefits in different types of states of the world and by illuminating the mechanisms underlying the welfare effects of disability programs, particularly the role of non-health risk.

How could expanding U.S. disability programs increase welfare despite prevalent mismatches with respect to health, non-health drivers, and reductions in work? Our results help reconcile this tension. The strong selection into disability receipt on the basis of non-health shocks means that mismatches with respect to health do not greatly decrease - and in fact appear to increase - the value of USDP. Non-health drivers of enrollment do not just drive up the costs of USDP, they also drive up the benefits in terms of insuring non-health risk. With respect to effects on labor supply, we do not provide new evidence on this question but instead quantify the implications of existing evidence for the value of USDP. Our analysis highlights the importance of a less-discussed aspect of the existing evidence: that marginal disability recipients, despite their non-negligible counterfactual labor force participation, have extremely low counterfactual earnings. ${ }^{7}$

This paper also contributes to the broader literature on the take-up and targeting of government programs. The main focus of this literature has been incomplete takeup (see Currie, 2006, for a review), with more recent work shedding light on the normative implications of incomplete take-up by studying the characteristics of those who do versus do not take up benefits. ${ }^{8}$ We find, in the context of USDP, that

\footnotetext{
${ }^{6}$ Bound et al. (2004) find that the typical worker would gain from a government budget-neutral marginal expansion of SSDI. Chandra and Samwick (2009) and Meyer and Mok (2019) find that disability programs, together with other programs, provide valuable but incomplete insurance against health risk. Low and Pistaferri (2015) estimate a structural life-cycle model and find that expanding USDP would increase welfare. Cabral and Cullen (2019) use the demand for private disability insurance to bound the value of public disability benefits and find a high lower bound. The finding by Gelber, Moore and Strand (2018) that larger SSDI payments reduce mortality is in keeping with these welfare results.

${ }^{7}$ For example, using the quasi-random assignment of applicants to adjudicators, Maestas, Mullen and Strand (2013) find that SSDI reduces the labor force participation of applicants on the margin of program entry by 28 percentage points, but that such applicants have average counterfactual earnings of just $\$ 6,000-\$ 9,000$ per year. Using a similar strategy, French and Song (2014) find that in the ten years after the SSDI/SSI decision, counterfactual earnings actually decline in later years after reaching a maximum of about $\$ 5,000$ per year around year five. Of course, these estimates do not reveal why counterfactual earnings are so low-whether because of health, skills, work ethic, etc.-which is relevant for certain non-welfarist perspectives.

${ }^{8}$ See, e.g., Bhargava and Manoli (2015); Alatas et al. (2016); Deshpande and Li (2019); Finkelstein and Notowidigdo (2019); Lieber and Lockwood (2019); Homonoff and Somerville (2020).
} 
incomplete take-up among more-severe individuals significantly increases the ex ante value of the program. Improper take-up, by contrast, has received much less attention in economic research, despite being central to public debates, from that in the 1970s about "welfare queens" to those more recently about disability awards and EITC overpayments. ${ }^{9}$ Our paper finds that benefits to less-severe individuals, which can be thought of as improper take-up relative to a specific benchmark, account for nearly one-half of the high value of USDP. Given that the risk of experiencing a more-severe work-limiting health condition might be the biggest risk that people face, our finding that the value of USDP is driven to such a large extent by mismatches with respect to health - i.e., by selective take-up with respect to other risks - suggests that selective take-up with respect to risks beyond a program's primary aim might be important in other applications as well.

\section{Theory: Non-health risk, mismatches with re- spect to health, and the value of disability in- surance}

Our goal is to go "beyond health" to determine the value of disability programs and their mismatches with respect to health accounting for non-health risk. Consider a simple model in which an individual faces two kinds of risk: health and non-health, where $h$ is the severity of the health shock and $n$ is the seriousness of the non-health shock. Consider a "health-based perspective" in which the objective of disability insurance is to provide benefits to the individual if and only if they have suffered a health shock of severity $\bar{h}$ or greater. This perspective divides the state space into two sets: states in which the individual has versus has not experienced a qualifying health shock: $h \gtrless \bar{h}$. We label states in which $h \geq \bar{h}$ "health-shock" and states in which $h<\bar{h}$ "non-health-shock." There are two types of mismatches relative to this perspective: awarding benefits in a non-health-shock state (an inclusion mismatch)

\footnotetext{
${ }^{9}$ The main economic research on improper take-up is earlier work on disability programs (e.g., Parsons (1991); Diamond and Sheshinski (1995); Low and Pistaferri (2015)). Beyond disability, recent work on the EITC by Jones and Ziliak (2019) finds that many of the households that receive EITC benefits despite being ineligible have low incomes. Kleven and Kopczuk (2011) analyze in theory how efforts to establish eligibility for a program trade off inclusion and exclusion errors. They find that optimal programs feature errors of both kinds.
} 
and failing to award benefits in a health-shock state (an exclusion mismatch).

Now consider an alternative, "value-maximizing" perspective in which the goal is to maximize the ex ante value of disability insurance by providing benefits if and only if the insurance benefit exceeds the distortion cost-i.e., if and only if doing so produces positive (ex ante) surplus value, $s(h, n)>0$. As we derive formally in Section 5, the insurance benefit depends mainly on the marginal utility of income, and the distortion cost depends mainly on what earnings would have been in the absence of disability benefits ("counterfactual earnings"), reflecting the reduction in labor supply from receiving disability benefits. This perspective divides the state space into two sets: states in which the value of receiving disability benefits is greater or less than zero: $s(h, n) \gtrless 0$. There are two types of mismatches relative to this perspective: awarding benefits when doing so reduces the value of disability insurance, and failing to award benefits when doing so would have increased the value of disability insurance.

Figure 1 shows how these two perspectives divide the state space into four mutually exclusive, exhaustive sets. It depicts a hypothetical joint $(h, s(h, n))$ distribution in the natural case in which health is a strong but noisy indicator of surplus. Health is likely a strong indicator of the value of receiving disability benefits because health shocks increase health spending and limit earning opportunities, and so tend to increase marginal utility and decrease counterfactual earnings. These two perspectives agree on providing benefits in the "Northeast" quadrant, states in which the individual suffers a health shock and receiving disability benefits produces positive surplus. They also agree on not providing benefits in the "Southwest" quadrant (likely the vast majority of states), states in which the individual does not suffer a health shock and receiving disability benefits produces negative surplus.

Yet the value of receiving disability benefits in a particular state is not entirely determined by the health shock. Insurance value is likely increasing in the seriousness of the non-health shock since transfers into states in which marginal utility is high provide valuable insurance, regardless of why marginal utility is high. In terms of distortions, benefits in states in which counterfactual earnings are low tend to have low efficiency costs regardless of why counterfactual earnings are low. In Figure 1, while $s(h, n)$ is increasing in $h$ on average, variation in $n$ causes it to vary around that average. As a result, the two perspectives occasionally disagree on whether benefits should be provided. They disagree about states in the "Southeast" quadrant, in which 
the individual suffers a health shock but the non-health shock is sufficiently favorable (e.g., high spousal earnings) to make surplus negative. The perspectives also disagree about states in the "Northwest" quadrant, in which the individual does not suffer a health shock but the non-health shock (e.g., productivity shock not insured by UI) is sufficiently unfavorable to make surplus positive.

Figure 1: Health-based vs. value-maximizing classifications of states

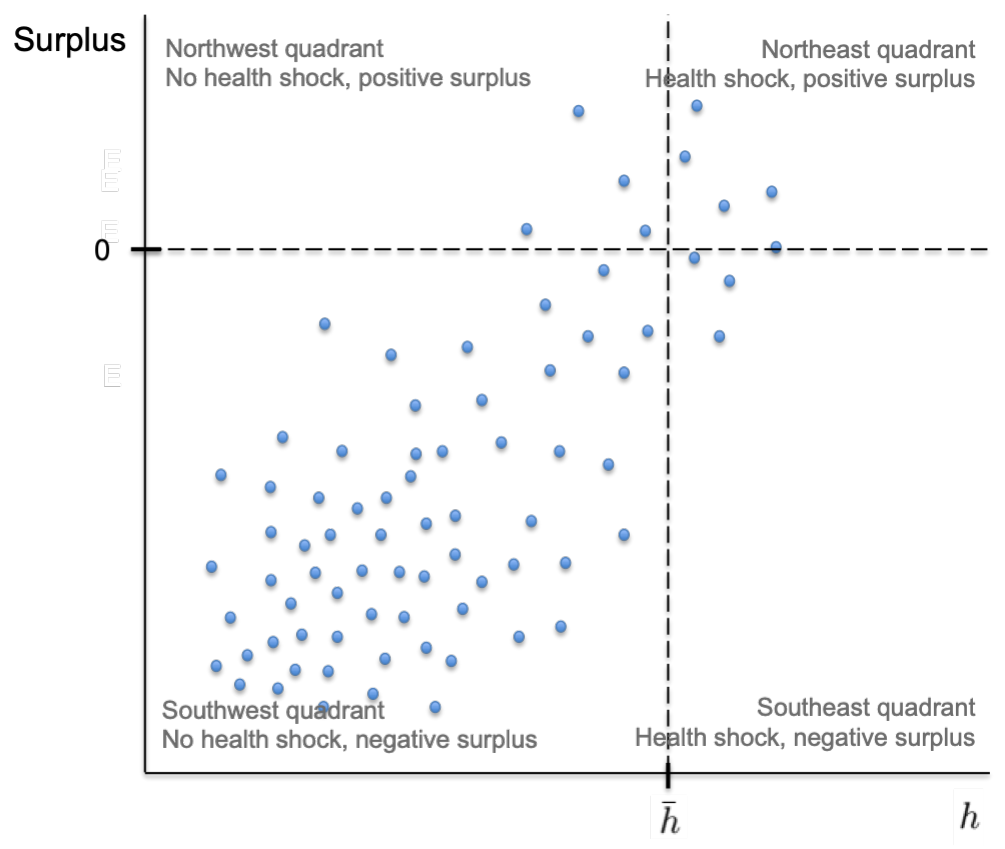

Notes: Figure shows how health-based and value-maximizing perspectives classify states of the world into those in which disability benefit receipt is versus is not desired. The $\mathrm{x}$-axis measures the severity of the health shock, $h$. The y-axis measures the ex ante surplus of receiving disability benefits. From a health-based perspective, disability benefit receipt is desired if and only if $h \geq \bar{h}$. From a valuemaximizing perspective, disability benefit receipt is desired if and only if $s(h, n)>0$, where $n$ is the seriousness of the non-health shock. These two perspectives both desire disability benefit receipt in states in the Northeast quadrant and non-receipt in states in the Southwest quadrant, but differ in their assessment of states in the Northwest and Southeast quadrants. $E(s \mid M)$ denotes mean surplus for $h \geq \bar{h}$ states, and $E(s \mid L)$ denotes mean surplus for $h<\bar{h}$ states. The blue dots depict a hypothetical joint $(h, s(h, n))$ distribution in the natural case in which health is a strong but noisy indicator of surplus.

In settings with substantial non-health risk, the value of disability insurance and the costs of its mismatches with respect to health depend crucially on the extent to which they insure or exacerbate non-health risk, which in turn depends on selection into disability receipt on the basis of non-health shocks. Mismatches with respect to health necessarily reduce the extent to which disability insurance insures health 
risk - in this context, the risk of experiencing a health shock $(h \geq \bar{h})$ - by reducing the extent to which disability insurance transfers from non-health-shock to health-shock states. But mismatches could either insure or exacerbate non-health risk, making their net effect on the insurance value of disability insurance theoretically ambiguous. If individuals with more-serious non-health shocks are more (less) likely to receive disability benefits conditional on health, then mismatches with respect to health insure (exacerbate) non-health risk. ${ }^{10}$ Assuming that health is a strong indicator of the value of receiving disability benefits, a representative exclusion mismatch - the failure to provide benefits in a state with surplus $E(s(h, n) \mid M)$-would forego costeffective insurance. Similarly, a representative inclusion mismatch — providing benefits in a state with surplus $E(s(h, n) \mid L)$ - would both exacerbate risk (by transferring to a state with below-average marginal utility) and involve substantial efficiency costs (by creating a large labor supply distortion).

But the actual inclusion and exclusion mismatches of a particular disability program may not be representative if the program's tags and screens lead to systematic selection into applying for and being awarded disability insurance. The U.S. SSDI and SSI programs, for example, use a vocational grid that takes into consideration certain non-health characteristics ("tags") in award decisions, such as an applicant's age, education, and work experience. SSDI and SSI also impose restrictions on applicants and recipients ("screens"), such as earnings restrictions and a complicated application process. ${ }^{11}$ Systematic selection could either increase or decrease the cost of actual mismatches relative to representative ones. For example, Deshpande and Li (2019) find that higher application costs disproportionately discourage individuals with relatively severe conditions and limited resources from applying for SSDI and SSI benefits. In Figure 1, such an unfavorable exclusion mismatch would be in the

\footnotetext{
${ }^{10}$ More precisely, exclusion mismatches insure risk within the set of states with health shockswhich we will mostly refer to as "non-health risk," though it could reflect a mix of health and non-health risk as defined by $h$ and $n$-if and only if mean marginal utility in health-shock recipient states exceeds that in health-shock non-recipient states, and inclusion mismatches insure risk within the set of states without health shocks (also "non-health risk") if and only if mean marginal utility in non-health-shock recipient states exceeds that in non-health-shock non-recipient states. The less variable is health within health-shock and non-health-shock states, the greater the extent to which within-health-shock and within-non-health risk reflects non-health risk as defined by $n$.

${ }^{11}$ Some screens are chosen intentionally to try to improve targeting, such as the restrictions on the earnings of applicants and recipients. Others, such as the complicated application process and the uncertainty in award decisions, are unintentional byproducts of program administration but can still be crucial to a program's targeting properties (Kleven and Kopczuk, 2011).
} 
"Northeast" quadrant (health shock and high surplus). On the other hand, strict earnings limits might discourage applications in states in which the individual can find suitable employment despite a health shock. In Figure 1, such a favorable exclusion mismatch would be in the "Southeast" quadrant (health shock but low surplus). Whether a disability program's tags and screens create value-enhancing or -reducing selection is ultimately an empirical question, one we aim to answer for U.S. disability programs in the following positive and normative analyses.

\section{$3 \quad$ Institutional setting and data}

Social Security Disability Insurance (SSDI) and Supplemental Security Income (SSI) (collectively "USDP") are intended to provide assistance to Americans who cannot work because of a severe health condition. SSDI and SSI use the same definition of disability. ${ }^{12}$ Non-health factors, such as age and education, factor in through the medical-vocational grids. ${ }^{13}$ For SSDI, eligibility is limited to individuals with qualifying earnings histories. The average annual SSDI cash benefit is around $\$ 15,000$, and beneficiaries qualify for Medicare after a two-year waiting period. ${ }^{14}$ Disabled workers are not permitted to earn more than the substantial gainful activity (SGA) level, which was $\$ 1,260$ per month $(\$ 15,120$ per year $)$ in 2020 . SSI is a means-tested program that has the same medical eligibility requirements and SSA adjudication process as SSDI but does not require a work history. The maximum federal SSI benefit for an individual was $\$ 783$ per month $(\$ 9,396$ per year) in 2020 , and the SSI benefit is reduced by 50 cents for each dollar of earnings. SSDI and SSI recipients receive periodic medical reviews in which the adjudicator considers the recipient's medical condition and work activity. To provide a comprehensive picture of U.S. disability

\footnotetext{
${ }^{12}$ Under Social Security rules, someone is considered disabled if (i) "[they] cannot do work that [they] did before," (ii) "[SSA] decide[s] that [they] cannot adjust to other work because of [their] medical condition(s)," and (iii) "[their] disability has lasted or is expected to last for at least one year or to result in death" (see https://www.ssa.gov/benefits/disability/qualify.html).

${ }^{13}$ This is a key difference between SSDI and SSI's eligibility rules, which account for certain nonhealth factors, and our classification of individuals on the basis of health alone. As a result, some correct awards under SSDI and SSI's rules are mismatches with respect to health by our definition, and some incorrect awards under SSDI and SSI's rules are not mismatches with respect to health by our definition. Our goal is not to judge SSDI and SSI's alignment with their rules but to characterize the health and non-health characteristics of recipients and non-recipients and to derive the implications for the value of benefits to different groups.

${ }^{14}$ Annual Statistical Report on the Social Security Disability Insurance Program, 2018.
} 
programs, we consider the SSDI and SSI programs together in our main analysis. We provide estimates for SSDI alone in Appendix J.

In Section 4, we use a combination of survey data and administrative data to study the characteristics of different groups of working-age households by their USDP status and severity. The first data source is the Panel Study of Income Dynamics (PSID), which we use to estimate differences by severity and USDP status in consumption, adverse non-health events (e.g., job loss), and resources (e.g., marriage). The main advantages of the PSID are its measures of consumption and adverse events and its long panel structure. We also use Social Security Administration data to measure adverse non-health events for more- and less-severe recipients. In particular, we measure mass layoffs as well as bankruptcy, eviction, and foreclosure from the data compiled by Deshpande, Gross and Su (2019). In Section 5, we use PSID data on consumption and earnings, together with quasi-experimental estimates from French and Song (2014), to estimate the surplus from disability benefits to different groups. Appendix A includes more detail on all data sources, and Appendix B discusses the robustness of the main results to measurement error in severity and disability receipt. Our findings suggest that measurement error usually, though not always, works against our main conclusions.

\section{Positive analysis: Non-health risk and selection into U.S. disability programs}

Our goal is to understand selection into U.S. disability programs on the basis of nonhealth shocks conditional on health. To that end, we characterize mismatch groupsless-severe recipients (L-DI) and more-severe non-recipients (M-DI) - on non-health dimensions. We focus on non-health characteristics likely to be predictive of the key determinants of the value of receiving disability benefits: the marginal utility of income and counterfactual earnings. ${ }^{15}$

\footnotetext{
${ }^{15}$ For simplicity, in the main text we present raw comparisons without controls or error bars. Results with different sets of controls for ability and with confidence intervals are presented in Appendix Figure F1. Within-ability comparisons are relevant for the insurance and welfare values of disability insurance, since across-ability insurance or redistribution can be accomplished (or offset) by the income tax and transfer system. Controlling for measures of ability tends to reduce the differences between recipients and non-recipients, but the differences remain large and the key conclusions are unchanged. Appendix Figure G1 compares education level, our main measure of ability group,
} 
Fact 1: On average, more-severe households are worse off than less-severe households by all measures, health and non-health, but there is substantial variation. Figure 2a shows that average consumption for households with moresevere conditions is just one-half that of households with less-severe conditions. This pattern is consistent across all of the measures that we observe: Having a more-severe health condition is strongly associated with lower living standards, lower earnings, and more adverse non-health events, even after controlling for proxies for ability group. Yet these strong average tendencies mask substantial variation within each severity group. For example, Figure 2a also shows that the bottom decile of households with less-severe conditions have consumption significantly below the mean among households with more-severe conditions, while the top decile of households with more-severe conditions have consumption above the mean among households with less-severe conditions. More generally, across different measures, we find that although health is strongly associated with better circumstances, it is far from a perfect indicator.

Fact 2: Less-severe recipients (L-DI) are much worse off than less-severe non-recipients (L-NDI), and by many non-health measures are even worse off than more-severe recipients (M-DI). Figure 2a shows that average consumption among L-DI is just over one-half that of L-NDI. This pattern is consistent across all of the measures that we observe: L-DI are substantially worse off than L-NDI, with substantial differences even after controlling for proxies for ability group (Appendix Figure F1). In fact, L-DI are so strongly selected that on non-health dimensions they are comparable to, and even sometimes worse off than, M-DI. Figure 2a shows that L-DI and M-DI have similar current consumption levels. To avoid measuring the causal effect of receiving disability benefits, we also go back to the year before each recipient started receiving benefits and find that L-DI and M-DI are equally likely to be at the bottom of the consumption distribution prior to receiving benefits (see Appendix Figure G2). ${ }^{16}$

In SSA administrative data, we find that L-DI experience adverse non-health

across USDP-by-severity groups. Appendix Figures J1 and J2 show the main results for SSDI only (excluding SSI). The results for SSDI are similar to the main results, with the exception that more-severe non-(SSDI)recipients look worse off because they include a substantial number of SSI recipients. Sample sizes for SSI-only are too small to generate precise estimates.

${ }^{16}$ To be sure, consumption and the other measures we study are determined by both health and non-health shocks. Since L-DI are by definition better off on health than M-DI, the fact that L-DI look similar to or worse than M-DI on these measures suggests that non-health shocks are worse for L-DI. 
Figure 2: Fact 2: L-DI similar to or worse off than M-DI on non-health measures

(a) PSID: Consumption

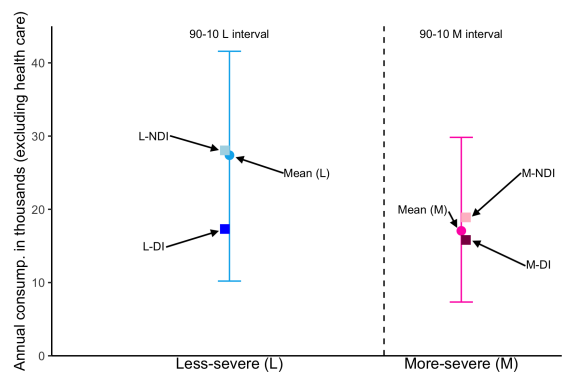

(c) PSID: Outside resources

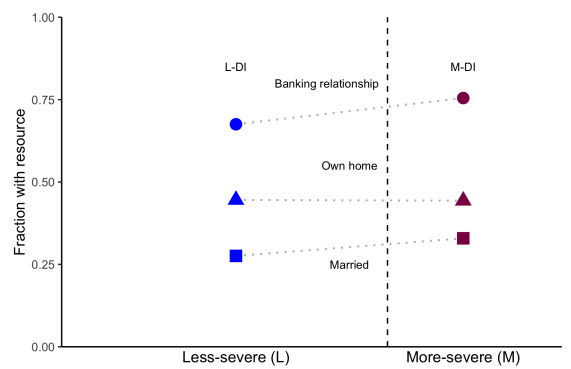

(b) Admin data: Prior to USDP receipt

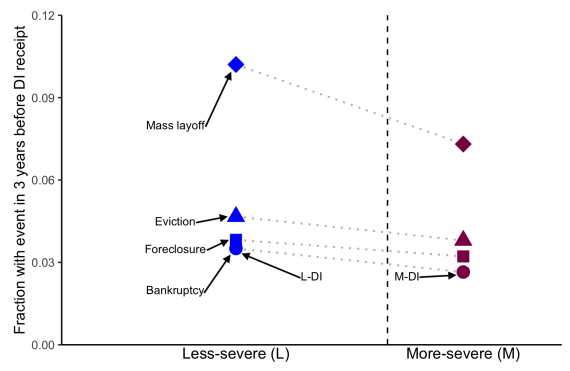

(d) PSID: Earnings at age 35

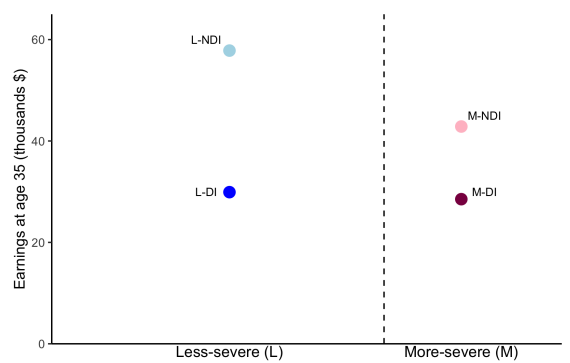

Notes: Figures 2a, 2c, and 2d present data from the PSID. Figure 2a presents statistics on consumption in the 2017 PSID for less-severe non-USDP-recipients (6,312 L-NDI), more-severe non-recipients (250 M-NDI), less-severe recipients (443 L-DI), and more-severe recipients (316 M-DI). Household consumption excludes health care and is divided by the square root of household size. Figure 2c presents rates of marriage, banking relationship, and homeownership for M-DI and L-DI (exact PSID questions in Appendix Table I4). Figure 2d presents average earnings at head age 35 (in 2016 dollars) for households that did not receive USDP benefits before age 36 and can be tracked back to age 35: 1,923 L-NDI, 90 M-NDI, 93 M-DI, and 152 L-DI. In all three PSID figures, "more-severe" is defined as self-reporting that a health condition limits "a lot" the amount of work one can do (vs. "somewhat," "just a little," or "not at all" [or no condition]). Figure $2 \mathrm{~b}$ presents rates of adverse financial events in the three years before receiving USDP for individuals who receive USDP benefits in SSA administrative data. The mass layoff sample (510,000 L-DI, 1.4M M-DI) is USDP recipients in the 831 records between 1990 and 2016 that appear in the Continuous Work History (CWHS). The bankruptcy sample is USDP recipients in the 831 files between 1995 and $2009(4.9 \mathrm{M}$ L-DI, 8.4M M-DI). The foreclosure sample is approved USDP applicants in the 831 files between 2005 and 2014 who are homeowners (700,000 L-DI, 1.4M M-DI). The eviction sample is approved USDP applicants in the 831 files between 2005 and 2014 who are not homeowners (590,000 L-DI, 1.5M M-DI). "More-severe" in Figure $2 \mathrm{~b}$ indicates recipients allowed at the initial state DDS level, and "less-severe" indicates recipients allowed upon appeal. 
events at rates that are similar to or higher than those of M-DI. Figure $2 \mathrm{~b}$ shows that L-DI are more likely than M-DI to have experienced a mass layoff prior to receiving disability benefits. The mass layoff rate is $10.2 \%$ for L-DI and $7.3 \%$ for M-DI in the three years before entry, and this difference remains even after conditioning on working. ${ }^{17}$ Figure 2b, on adverse financial events in SSA administrative data linked to nationwide financial records, shows a similar pattern. In the years prior to receiving disability benefits, L-DI are more likely than M-DI to have experienced bankruptcy (3.5\% vs. $2.6 \%$ ), foreclosure (3.8\% vs. $3.2 \%)$, and eviction (4.7\% vs. $3.8 \%) .{ }^{18}$ PSID measures of adverse non-health events reinforce the results from the SSA administrative data: L-DI and M-DI in the PSID experience similarly high rates of involuntary job loss, distressed moves, and divorce in the four years prior to receiving disability benefits (Appendix Figure G3). Overall, the likelihood of experiencing any of these events in the four years prior to receiving disability benefits is $57 \%$ for L-DI and $50 \%$ for M-DI. ${ }^{19}$

In addition to adverse non-health events, we also analyze how L-DI are selected on resources available to cope with adverse events. As shown in Figure 2c, we find that L-DI are less likely than M-DI to be married (28\% vs. $33 \%$ ) or to have a banking relationship ( $68 \%$ vs. $75 \%$ ), and are similarly likely to own a home (45\% vs. $44 \%$ ). To account for the possible causal effect of receiving disability benefits on resources, we go back to the year before disability receipt and find a similar pattern (Appendix Figure G8a). Prior to disability receipt, L-DI are also less likely to have either private or public health insurance (67\% vs. 75\%, from Appendix Figure G8b), less likely to receive public transfers ( $37 \%$ vs. $40 \%$ for food stamps, from G8c), and less likely to receive help from relatives ( $23 \%$ vs. $25 \%$, from G8d). ${ }^{20}$

These results suggest that L-DI are highly selected on one key determinant of the value of receiving disability benefits: marginal utility. What about the other key

\footnotetext{
${ }^{17}$ Overall, mass layoff rates for disability recipients at entry are about twice those of non-recipients at the same ages (see Appendix Figure G4).

${ }^{18}$ Appendix Figure G5 breaks down the rates of adverse financial events into finer groups: initial allowance at Step 3 (meets medical listings), initial allowance at Step 5 (based on vocational grid), allowed on appeal, and never allowed.

${ }^{19}$ These likelihoods far exceed the baseline level among non-recipients: at entry, disability recipients are $70 \%$ more likely than non-recipients of the same age to experience these adverse events (see Appendix Figure G6).

${ }^{20}$ Relative to the baseline severity definition, the results are even stronger when using the broader "a lot + somewhat" definition and are similar when using the "physical + mental health" definition (see Appendix Figure G7).
} 
determinant, counterfactual earnings? Although we do not have a direct measure of counterfactual earnings, Figure 2d shows average earnings of the household head at age 35, well before most individuals start receiving disability benefits but after at least some health and non-health shocks are realized. Households who later become L-DI have head earnings at age 35 similar to the age-35 head earnings of households who later become M-DI. ${ }^{21}$

These results suggest that L-DI benefits are less costly than benefits to representative less-severe individuals would be. How do L-DI come to receive disability benefits in the first place? From the PSID, about 25\% had a more-severe condition when they applied, even though they no longer have a more-severe condition. Another 15\% received UI immediately before applying for disability benefits, suggesting that they may have turned to U.S. disability programs as a form of permanent insurance following a qualifying job loss. Another 40\% experienced some observable shock (job loss, distressed move, or divorce) before applying for disability benefits but never received UI. The remaining $20 \%$ have no observable shock prior to applying for disability benefits but have low resources on average. ${ }^{22}$

\section{Fact 3: More-severe non-recipients (M-NDI) are better off on non-health measures than both more-severe and less-severe recipients. Figure 2a shows} that M-NDI consumption is on average slightly greater than M-DI consumption, though still well below L-NDI consumption. Figure 3a shows a similar pattern in the likelihood of experiencing an adverse non-health event (specifically, job loss, distressed move, or divorce) at different ages in the PSID. For each age range (25-34, 35-44, 45-54, 55-64), we plot on the "more-severe" side the rate of adverse non-health events for M-NDI at that age and for M-DI who begin receiving disability benefits in that age range at that age. We find that M-NDI are 10-30\% less likely in every age range to have experienced an adverse non-health event. ${ }^{23}$ Turning to outside resources, we find in Figure $3 \mathrm{~b}$ that M-NDI are more advantaged than M-DI in the year of

\footnotetext{
${ }^{21}$ Because disability receipt tends to last many years, the value of USDP depends not only (or even primarily) on counterfactual earnings at the time of entry but on counterfactual earnings for many years thereafter. We discuss quasi-experimental evidence on this key issue in the normative analysis (Section 5). Research suggests that events like mass layoffs, which are more common for L-DI than M-DI, are associated with long-term earnings losses (e.g., Jacobson, LaLonde and Sullivan, 1993).

${ }^{22}$ From the 2014 SIPP linked to SSA data, among L-DI, 30\% are allowed due to being deemed to meet medical eligibility criteria (Step 3 of the disability determination process), $41 \%$ due to being deemed to have no capacity for any work based on the vocational grid (Step 5), and $25 \%$ on appeal.

${ }^{23}$ Appendix Figures G9 and G10 show results for head and spouse job loss, distressed move, and divorce separately.
} 
disability onset. M-NDI are more likely than M-DI to be married (49\% vs. 35\%), to have a banking relationship (66\% vs. $58 \%$ ), and to own a home (47\% vs. $45 \%$ ). With respect to counterfactual earnings, Figure $2 \mathrm{~d}$ shows that the age-35 head earnings of households that later become M-NDI are almost $50 \%$ greater than those of households that later become M-DI, though still substantially lower than those of households that later become L-NDI.

Figure 3: Fact 3: M-NDI better off than M-DI on non-health measures

(a) PSID: Any adverse life event

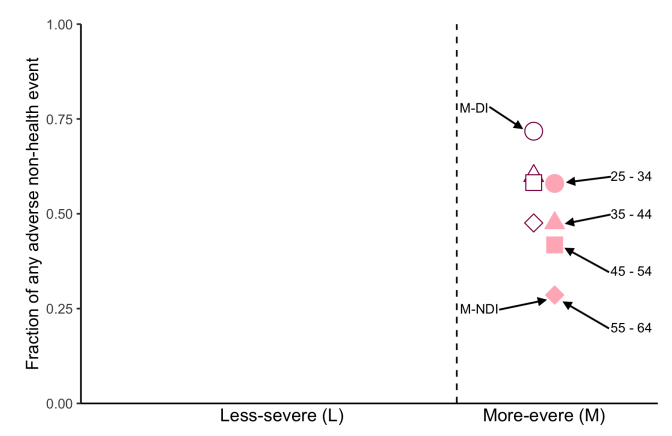

(b) PSID: Resources at more-severe onset

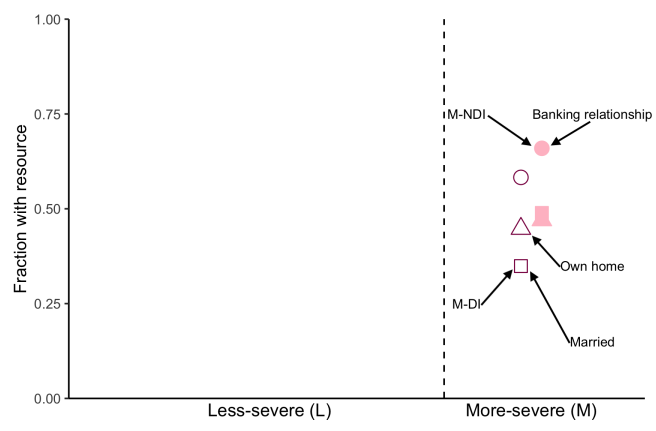

Notes: Figure 3a presents rates of experiencing an "adverse life event" - head or spouse job loss, involuntary move, or divorce - at various ages for households in the PSID, by USDP status, health status, and age at USDP entry. Households are first categorized by their USDP status: whether they ever received USDP (DI) or never received USDP (NDI). DI are further classified by their health status at USDP entry and their age at entry, and NDI are further classified by whether they ever had a more-severe health condition. The figure plots the share experiencing an adverse life event in a specific age range (e.g., 25-34 and 35-44) among M-NDI and among M-DI who also entered USDP at that age. The sample sizes for age groups 25-34, 35-44, 45-54, and 55-64 are 896, 1199, 1054, and 848 for M-NDI; and 97, 211, 243, and 348 for M-DI. Job loss includes "involuntary" reasons for separation: strike/lockout, laid off/fired, or company going out of business or leaving town (exact PSID question in Appendix Table I2). Distressed move includes external events like eviction, contraction of housing (less space/less rent), and other reasons potentially indicating distress, such as saving money (exact PSID question in Appendix Table I3). Divorce is defined as being married in a previous survey year but not in this survey year (see Appendix Table I2). Figure 3b presents rates of marriage, banking relationship, and homeownership one year prior to the year of more-severe onset for M-NDI (207) and M-DI (240) (exact PSID questions in Appendix Table I4). "More-severe" is defined as self-reporting that a health condition limits "a lot" the amount of work one can do (as opposed to "somewhat," "just a little," or "not at all" [or no health condition]). Markers for the two groups are offset to facilitate easier reading of the graph, not as a representation of relative severity.

These results suggest that were M-NDI to receive disability benefits, such benefits would be less valuable than benefits to representative more-severe individuals. Why do M-NDI not receive disability benefits? From the SIPP-SSA linked data, we find that about $45 \%$ of M-NDI can be explained by mistakes in the decision process: 
individuals with more-severe conditions who applied but were rejected by SSA on medical grounds. ${ }^{24}$ The remaining $55 \%$ of M-NDI do not apply. This self-selection out of applying for disability benefits appears likely to insure non-health risk: Relative to M-NDI who apply, M-NDI who do not apply have higher educational achievement (3.0\% vs. $11 \%$ college degrees), higher rates of marriage and homeownership (46\% vs. $55 \%$, and $52 \%$ vs. $61 \%$ ), and lower rates of "very low" food security (23\% vs. 17\%). Still, a nontrivial share of M-NDI who do not apply are disadvantaged.

\section{Normative analysis: Estimating the value of U.S. disability programs and their mismatches}

\subsection{Theory: Value of receiving disability benefits in different states}

Our goal is to estimate the ex ante net value of disability benefits in different states of the world: the extent to which their ex ante value exceeds their cost, including cost from the distortions created by disability benefits receipt. ${ }^{25}$ Like all welfare analyses, ours relies on assumptions for mapping observable characteristics into unobservable welfare. In our case, the key assumptions are that individuals optimize and that there are no externalities beyond "fiscal externalities": effects of behavioral responses on net government spending. In the empirical implementation, discussed in Section 5.2, we also make assumptions about marginal utility that determine the value of transferring resources from some states to others and so the insurance value of disability benefits.

Ex ante value of disability benefits in states $\Omega_{b}: E A W T P_{\theta}\left(\Omega_{b}\right)$. Ex ante "risk type" $\theta$ faces a given set of possible ex post states of the world, $\Omega_{\theta}$. We wish to assess the ex ante value to $\theta$ of disability benefits in states $\Omega_{b} \subseteq \Omega_{\theta}$ (e.g., states in which the individual is a non-recipient with a health shock). To first order, the ex ante value

\footnotetext{
${ }^{24}$ From the 2014 SIPP linked to SSA data, among M-NDI who apply and are rejected, $12 \%$ are rejected due to being deemed to have no severe impairment (Step 2 of the disability determination process), $13 \%$ due to being deemed to have capacity for previous work (Step 4), and $67 \%$ due to being deemed to have capacity for any work based on the vocational grid (Step 5).

${ }^{25}$ To simplify the exposition, we refer to "states of the world" $\omega$ rather than "state-times" $\omega_{t}$, but the distributions, probabilities, and conditional means of interest are across state-times: across both lifetime states of the world and time periods within each lifetime state of the world, as in Chetty (2006).
} 
to type $\theta$, in terms of income in states $\Omega_{\tau}$, of disability benefits in states $\Omega_{b}$ is the $E A W T P_{\theta}\left(\Omega_{b}\right)$ that solves

$$
\underbrace{p\left(\Omega_{b} \mid \theta\right) E\left(\lambda_{\omega} \times W T P_{\omega} \mid \theta, \Omega_{b}\right)}_{\text {MB of disability benefits in states } \Omega_{b}}=\underbrace{p\left(\Omega_{\tau} \mid \theta\right) E\left(\lambda_{\omega} \mid \theta, \Omega_{\tau}\right) E A W T P_{\theta}\left(\Omega_{b}\right)}_{\text {MC of giving up } E A W T P_{\theta}\left(\Omega_{b}\right) \text { in states } \Omega_{\tau}},
$$

where $p(\cdot)$ is the probability operator, $\lambda_{\omega}$ is the marginal utility of income in state $\omega$, $W T P_{\omega}$ is the ex post value of disability benefits in state $\omega$, and here, with some abuse of notation, $\Omega_{X}$ refers to the event that the realized state $\omega$ is in the set of states $\Omega_{X}$ $\left(\omega \in \Omega_{X}\right)$. The left-hand-side is the ex ante marginal benefit of disability benefits in $\Omega_{b}$ states. The right-hand-side is the ex ante marginal cost of giving up $E A W T P_{\theta}\left(\Omega_{b}\right)$ worth of income in $\Omega_{\tau}$ states. Solving for $E A W T P_{\theta}\left(\Omega_{b}\right)$ and rearranging yields

$$
E A W T P_{\theta}\left(\Omega_{b}\right)=\underbrace{\frac{p\left(\Omega_{b} \mid \theta\right)}{p\left(\Omega_{\tau} \mid \theta\right)}}_{\pi} E[\underbrace{\left(\frac{\lambda_{\omega}}{E\left(\lambda_{\omega} \mid \theta, \Omega_{\tau}\right)}\right)}_{\left(1+M_{\omega}\right)} W T P_{\omega} \mid \theta, \Omega_{b}] .
$$

The first term, $\pi$, is the no moral hazard actuarially fair price of income in $\Omega_{b}$ states in terms of income in $\Omega_{\tau}$ states. The term in the expectation that multiplies the ex post value of disability insurance, $W T P_{\omega}$, is one plus the "markup" on transfers from $\Omega_{\tau}$ to $\omega$ :

$$
M_{\omega} \equiv \frac{\lambda_{\omega}-E\left(\lambda \mid \theta, \Omega_{\tau}\right)}{E\left(\lambda \mid \theta, \Omega_{\tau}\right)} .
$$

The markup is the amount by which marginal utility in $\omega$ exceeds mean marginal utility in the states used to value disability insurance $\left(\Omega_{\tau}\right)$, as a share of the latter. One dollar worth of expected income in $\omega$ is worth $\$\left(1+M_{\omega}\right)$ of expected income in $\Omega_{\tau}$ states, so $M_{\omega}$ is the marginal insurance value of transferring resources across these states per dollar of such transfers.

\section{Ex ante cost to the government of providing disability benefits in states}

$\Omega_{b}: E A G_{\theta}\left(\Omega_{b}\right)$. The ex post cost to the government of the individual receiving disability benefits in state $\omega, G_{\omega}$, includes not only the cost of the disability benefit itself but also fiscal externalities on other aspects of the government budget from any induced behavioral responses, such as reductions in the net taxes paid by a recipient's household due to labor supply responses to receiving disability benefits. The ex ante expected cost to the government of type $\theta$ receiving disability benefits in states $\Omega_{b}$, 
per state of the world in which type $\theta$ pays associated taxes, is

$$
E A G_{\theta}\left(\Omega_{b}\right)=\pi E\left(G_{\omega} \mid \theta, \Omega_{b}\right)
$$

Ex ante surplus from disability benefits for type $\theta$ in states $\Omega_{b}: s_{\theta}\left(\Omega_{b}\right)$. Ex ante surplus from disability benefits for type $\theta$ in states $\Omega_{b}$, per state of the world in which type $\theta$ pays associated taxes, is

$$
s_{\theta}\left(\Omega_{b}\right)=g_{\theta} \times E A W T P_{\theta}\left(\Omega_{b}\right)-E A G_{\theta}\left(\Omega_{b}\right)
$$

where $g_{\theta}$ is the marginal cost to the government of providing $\$ 1$ worth of surplus to $\theta$ through the income tax and transfer system (the "inverse-optimum weight" in Hendren, 2020). ${ }^{26}$ The first term, $g_{\theta} \times E A W T P_{\theta}\left(\Omega_{b}\right)$, is how much it would cost the government to provide $E A W T P_{\theta}\left(\Omega_{b}\right)$ of surplus to $\theta$ via income tax cuts in $\Omega_{\tau}$ states. The second term, $E A G_{\theta}\left(\Omega_{b}\right)$, is how much it would cost the government to provide $E A W T P_{\theta}\left(\Omega_{b}\right)$ of surplus to $\theta$ via disability benefits in $\Omega_{b}$ states. The difference, $s_{\theta}\left(\Omega_{b}\right)$, therefore measures the surplus from disability benefits for type $\theta$ in states $\Omega_{b}$ in terms of net government revenue. It answers: How much net revenue would the government raise from the combination of (i) providing disability benefits to type $\theta$ in states $\Omega_{b}$ and (ii) raising taxes on $\theta$ exactly enough to leave $\theta$ indifferent between this hypothetical combined disability-insurance-and-tax policy and the status quo? The surplus is positive if and only if it is cheaper for the government to help $\theta$ by providing disability benefits in $\Omega_{b}$ states than by cutting $\theta$ 's income taxes in $\Omega_{\tau}$ states. The surplus is greater when: the value of disability benefits in $\Omega_{b}$ states is greater (greater $E A W T P$ ), the efficiency cost of disability benefits in $\Omega_{b}$ states is smaller (smaller $E A G$ ), and the efficiency gain from cutting income taxes in $\Omega_{\tau}$ states is smaller (greater $\left.g_{\theta}\right){ }^{27}$

Overall mean surplus to all types: $s\left(\left\{\Omega_{b}(\theta)\right\}_{\theta \in \Theta}\right)$. The overall mean social surplus from each type $\theta$ receiving disability benefits in states $\left\{\Omega_{b}(\theta)\right\}_{\theta \in \Theta}$, in terms

\footnotetext{
${ }^{26}$ The inverse-optimum weight, $g_{\theta}$, is the marginal rate of transformation from surplus to $\theta$ to net revenue to the government through the income tax system. An income tax cut that makes $\theta \$ 1$ better off costs the government $\$ g_{\theta}$ of net revenue, and an income tax hike that makes $\theta \$ 1$ worse off brings the government $\$ g_{\theta}$ of net revenue. Inverse-optimum weights are the social planning weights that would rationalize the status quo tax schedule as optimal.

${ }^{27}$ The ratio of the value of disability benefits to those of a cost-equivalent tax cut is $E A W T P_{\theta}\left(\Omega_{b}\right) /\left(M V P F_{\theta}(\right.$ tax cut $\left.) \times E A G_{\theta}\left(\Omega_{b}\right)\right)=g_{\theta} \times E A W T P_{\theta}\left(\Omega_{b}\right) / E A G_{\theta}\left(\Omega_{b}\right)=\left(s_{\theta}\left(\Omega_{b}\right)+\right.$ $\left.E A G_{\theta}\left(\Omega_{b}\right)\right) / E A G_{\theta}\left(\Omega_{b}\right)$.
} 
of net government revenue per taxpaying state, is the mean surplus across types,

$$
s\left(\left\{\Omega_{b}(\theta)\right\}_{\theta \in \Theta}\right)=E_{\theta}\left[s_{\theta}\left(\Omega_{b}(\theta)\right)\right] .
$$

\subsection{Empirical implementation}

Ex post value and cost. Our aim is to quantify, for different risk types $\theta$, the ex ante surplus from disability benefits, $s_{\theta}\left(\Omega_{b}\right)$ from equation (5), in each of four sets of states of the world: $\Omega_{b}=\Omega_{h-d i} \in$ \{more-severe recipient (M-DI), less-severe recipient (L-DI), more-severe non-recipient (M-NDI), less-severe non-recipient (L-NDI) . The key building blocks are the ex post value and ex post cost of disability benefits in different states.

We assume that the ex post value of disability benefits in state $\omega$ is

$$
W T P_{\omega}=\mathbb{1}\left(z_{\omega}^{D I=0} \leq \bar{z}\right) \times b
$$

where $z_{\omega}^{D I=0}$ is counterfactual earnings in state $\omega, \bar{z}$ is the USDP earnings limit, and $b$ is the USDP benefit. The indicator function indicates whether earnings in state $\omega$ would exceed the earnings limit if, counterfactually, the individual did not receive disability benefits and so was not subject to the earnings limit. This is a conservative first-order approximation that tends to understate the value of a disability benefit-like expansion of the budget constraint. ${ }^{28}$ The earnings limit, $\bar{z}$, is the annualized value of the Social Security Administration's earnings limit for SSDI recipients $(\$ 1,260$ per month in 2020 , or $\$ 15,120$ per year).

As a baseline, the benefit, $b$, is $\$ 13,000$, roughly the average annual cash benefit of disability recipients in recent years. This follows the literature on the welfare effects of USDP in excluding the health insurance component of disability benefits as a baseline given the likelihood that for many recipients it mainly displaces other forms

\footnotetext{
${ }^{28}$ For simplicity and because of measurement issues with determining SSDI and SSI eligibility for non-recipients in the PSID, we quantify the value of a SSDI-like expansion of the budget constraint rather than modeling SSI and SSDI separately. Equation (7) is a conservative approximation to this value in that it assumes that the ex post value of disability benefits is zero in states in which counterfactual earnings exceed the earnings limit $\bar{z}$, no matter how small the excess, whereas in reality someone whose counterfactual earnings were up to $(\bar{z}+b)$ could work less and consume more with disability benefits - and so potentially gain significantly. This assumption means that extended disability receipt in "lifetime states of the world" in which counterfactual earnings exceed the earnings limit is extremely socially costly on net, since it is all cost and no benefit, year after year.
} 
of subsidized health care cost sharing they otherwise would have received (see, e.g., Liebman, 2015). In Appendix Section C, we consider a wide range of assumptions about health insurance, including ones in which the health insurance component is more valuable in states in which the individual has a more-severe health condition.

We find in those cases that the health insurance component tends to modestly reduce the value of L-DI benefits relative to M-DI benefits (see Appendix Table F2). ${ }^{29}$

To be sure, this first-order approximation to the value of disability benefits does not account for any associated hassle or stigma costs. Moreover, this analysis of the value of disability benefits in different states of the world does not speak directly to specific policy reforms, since policies are limited by information and incentive compatibility constraints in the extent to which they can target particular states. This analysis does not capture, for example, application responses to policy reforms, which are potentially important for the costs of such reforms. In Appendix Section D, we consider three frequently-discussed policy reforms taking into account the limited evidence on application responses: limiting receipt by less-severe individuals, decreasing benefit levels, and decreasing the allowance rate.

The ex post cost to the government of the individual receiving disability benefits in state $\omega$ is

$$
G_{\omega}=b+\Delta_{\omega}
$$

where $\Delta_{\omega}$ is the increase in non-disability net government spending due to behavioral responses to receiving disability benefits in state $\omega$, such as losses in net tax revenue from earnings responses and changes in transfers from other programs. ${ }^{30}$ We assume

\footnotetext{
${ }^{29}$ Health insurance is a much smaller driver of the net value of USDP than of gross government expenditures on USDP in part because it displaces other forms of health care cost-sharing, including private health insurance (see the thoughtful discussion in Bound et al., 2004), other sources of government health insurance, and "informal health insurance" from charity care, bankruptcy, and bad debt. As Liebman (2015) notes, "[G]iven the expansions of Medicaid eligibility and subsidies for insurance purchase enacted as part of the Patient Protection and Affordable Care Act of 2010, many disability recipients would today be receiving free or heavily subsidized health insurance even if they were not receiving disability benefits" (131). For this reason and others, most papers on the value of USDP exclude health insurance, including Bound et al. (2004), Chandra and Samwick (2009), Low and Pistaferri (2015), Cabral and Cullen (2019), and Meyer and Mok (2019). We find that under plausible assumptions, health insurance decreases the ratio of the per-recipient surplus of L-DI to M-DI benefits from its baseline value of 0.78 to $0.74-0.77$ (see Appendix Table F2).

${ }^{30}$ Together, these definitions of ex post value (equation (7)) and ex post cost (equation (8)) imply that the fiscal externality $F E$ - the increase in government costs due to behavioral responses as a share of the cost were there no behavioral responses (the "mechanical effect" $M E$ ) -is $F E\left(\Omega_{b}\right)=$ $\frac{E A G_{\theta}\left(\Omega_{b}\right)}{M E_{\theta}\left(\Omega_{b}\right)}-1=\frac{\left[1-p\left(z_{\omega}^{D I=0} \leq \bar{z} \mid \theta, \Omega_{b}\right)\right] b+E\left(\Delta \omega \mid \theta, \Omega_{b}\right)}{p\left(z_{\omega}^{D I=0} \leq \bar{z} \mid \theta, \Omega_{b}\right) b}-1$.
} 
that $\Delta_{\omega}$ is $20 \%$ of the causal reduction in earnings from receiving disability benefits in state $\omega, \Delta_{\omega}=0.2 \times\left(z_{\omega}^{D I=0}-z_{\omega}^{D I=1}\right)$. This is an estimate of the reduction in income tax revenue due to labor supply responses to receiving disability benefits, based on Hendren and Sprung-Keyser's (2019) estimate of the average marginal net tax and transfer rate on the reduction in earnings from receiving disability benefits of $20 \%{ }^{31}$

Key determinants. The key determinants of both the ex post value and the ex post cost of disability benefits are counterfactual earnings with and without disability benefits $\left(z_{\omega}^{D I=1}\right.$ and $\left.z_{\omega}^{D I=0}\right)$. To construct counterfactual no-benefit earnings $\left(z_{\omega}^{D I=0}\right)$ for individuals who actually receive disability benefits, we use French and Song's (2014) quasi-experimental estimates of the effects of disability benefits on the earnings of individuals with different types of health conditions three years after the disability decision. We assume that counterfactual no-benefit earnings for individuals who receive disability benefits are observed (with-benefit) earnings from the PSID plus French and Song's (2014) estimated mean reduction in earnings due to disability benefits by detailed health condition. We assume that counterfactual with-benefit earnings $\left(z^{D I=1}\right)$ for individuals who do not receive disability benefits are the smaller of predicted counterfactual earnings based on French and Song (2014) and the SSDI earnings limit. It could be that these estimates of the effect of being awarded disability benefits understate the full causal effect of USDP on earnings - for example, if the long application process reduces the later earnings of individuals who are rejected (Parsons, 1991; Maestas, Mullen and Strand, 2013). It also could be that the longterm effects of disability benefits are larger than the short-term effects, especially if the non-health shocks experienced by less-severe recipients are temporary in nature. For these reasons, we test the robustness of our conclusions to much larger effects of disability benefits on earnings, for both more-severe and less-severe recipients, and find that our key conclusions are robust (see Appendix Table F3) ${ }^{32}$

\footnotetext{
${ }^{31}$ In principle, $\Delta_{\omega}$ includes changes in transfers from other programs as well, such as SNAP and TANF. In practice, Bound et al. (2004) find that the change in other program expenditures from marginal disability applications is less than $1 \%$ of the change in tax revenue from the earnings response.

${ }^{32}$ One consideration with using these estimates is heterogeneity in the earnings responses to disability benefits. French and Song (2014) estimate the (within-detailed health category) local average treatment effects of being awarded disability benefits on earnings among applicants on the margin of program entry. Applying these estimates to all states likely leads us to overstate earnings responses in states in which the individual receives disability benefits (since in many the individual is inframarginal), which tends to decrease the implied value of USDP. Another consideration is the time horizon. Receipt of disability benefits often lasts many years, so they are a costly way to insure
} 
The key determinant of the insurance value of disability insurance is marginal utility $\left(\lambda_{\omega}\right)$. We assume that marginal utility is a power function of non-health consumption, $\lambda=c^{-\gamma}$ (i.e., constant relative risk aversion utility), where $\gamma$ is the coefficient of relative risk aversion. We use PSID data on total household consumption excluding health care, since including health care consumption could artificially inflate the consumption level of households with more-severe health conditions. We adjust for household size by dividing household consumption by the square root of household size. We also impose an annual consumption floor at the 10th percentile of the consumption distribution. Using observed consumption tends to overstate the counterfactual no-benefit consumption of disability recipients (since it reflects disability benefits), and so to understate their no-benefit marginal utility and the ex ante value of disability benefits in that state. We measure the value of disability benefits to the household in terms of income in states in which they do not receive benefits, $\Omega_{\tau}=\Omega_{N D I}$.

Our baseline specification uses a coefficient of relative risk aversion of two and state-independent marginal utility. The functional form of marginal utility plays a crucial role in determining the value of transferring resources from some states to others and so in the insurance value of disability insurance. The assumed level of risk aversion is critical because it determines the magnitude of the gap in marginal utilities, and so the insurance value of transfers, for any given gap in consumption. For this reason, we test robustness to different levels of risk aversion and to state-dependent utility and find that our key conclusions are robust (see Appendix Table F4). ${ }^{33}$

transitory shocks. French and Song (2014) estimate counterfactual earnings for ten years after the disability award decision and find that earnings actually decline in later years after reaching a maximum of about $\$ 5,000$ per year around year five. This trajectory is in keeping with evidence from Jacobson, LaLonde and Sullivan (1993) and Sullivan and Von Wachter (2009) that displaced workers experience long-term earnings losses. Still, we probe the robustness of our estimates and find a positive surplus from disability benefits in less-severe recipient (L-DI) states for earnings reductions up to four times those estimated by French and Song (2014). Our results would be qualitatively similar using estimates from Maestas, Mullen and Strand (2013), but they estimate only employment effects (not earnings effects) by subgroup.

${ }^{33}$ As Chetty and Looney (2006) emphasize, a small consumption gap is consistent with a large marginal insurance value if the consumption gap is small because risk aversion is large (or vice versa). The evidence on state-dependence of marginal utility of consumption is mixed. For example, Finkelstein, Luttmer and Notowidigdo (2013) conclude that marginal utility is lower when health is worse, whereas Lillard and Weiss (1997) conclude that it is higher and Brown, Goda and McGarry (2016) find substantial heterogeneity across ages and disability types. We consider both directions in our robustness calculations. 
Risk types. As a baseline, we assume that an individual's risk type is determined by their education: $\theta \in\{$ high school dropout, high school graduate, some college, college plus $\}$. The conceptual experiment is that someone ex ante, knowing only what education group they will belong to, draws their state of the world from the cross-sectional distribution of households with a working-age head and with that education level. In other words, we take the cross-sectional distribution of households of a given education level to represent the distribution of possible ex post states of the world that someone with that education level faces ex ante. Ideally, the risk type would both isolate risk from heterogeneity and separate the ex ante population into groups with different ex ante earning ability, since the income tax and transfer system can redistribute across groups with different earnings levels. We consider other approaches for defining risk types and find that the key results are robust to plausible alternatives (see Appendix Table H2). Each risk type $\theta$ 's inverse optimum weight, $g_{\theta}$, is the within- $\theta$ average of Hendren's (2020) baseline estimates of inverse optimum weights by household income centile.

\subsection{Empirical estimates of the value of disability benefits in different states}

Figure 4a shows the empirical analogue of the theoretical Figure 1, and Table 1 reports related estimates. The results reveal two key findings. First, U.S. disability programs generate substantial ex ante surplus. We estimate that disability benefits as a whole are $64 \%$ more valuable than tax cuts with the same cost to the government would be. As a result, the annual ex ante surplus from USDP, measured in terms of government revenue, is $\$ 920$ per household or $\$ 81$ billion in aggregate (based on there being about 88 million working-age households in the U.S.). This means that were the government to abolish USDP, the tax cuts necessary to leave individuals unharmed relative to the status quo would cost the government $\$ 920$ per household per year more than what it would save from abolishing USDP. Second, USDP mismatches with respect to health are not costly - they are highly valuable. We estimate that mismatches produce an annual ex ante surplus, in terms of government revenue, of $\$ 510$ per household or $\$ 45$ billion in aggregate. This is mostly attributable to benefits in less-severe states:

Such benefits are worth 57\% more than cost-equivalent tax cuts and produce ex ante surplus of $\$ 440$ per household. In fact, benefits in less-severe states (L-DI) appear to 
Figure 4: Surplus and its determinants: markup and counterfactual earnings

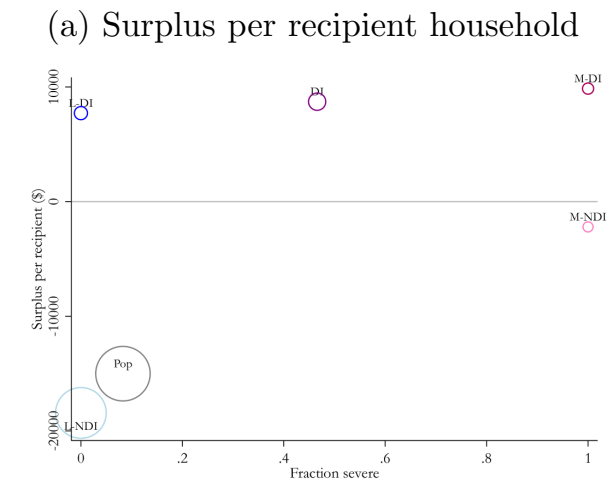

(b) Markup and counterfactual earnings

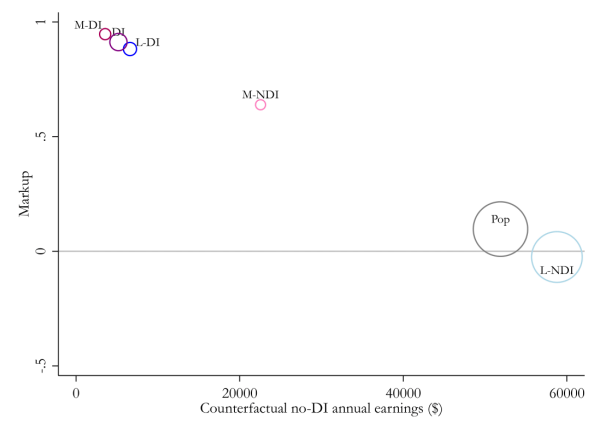

Notes: Figure 4a, the empirical analogue of Figure 1, plots surplus per recipient household, $p\left(\Omega_{\tau}\right) s / p\left(\Omega_{b}\right)$, against the fraction more-severe for the following sets of states of the world, $\Omega_{b}$ : all states (Pop); states in which the household receives USDP benefits (DI), including when moresevere (M-DI) and less-severe (L-DI); and states in which the household does not receive USDP benefits (NDI), including when more-severe (M-NDI) and less-severe (L-NDI). Surplus $s$, defined in equation (6), is in units of government revenue per $\Omega_{\tau}$ state, so $p\left(\Omega_{\tau}\right) s / p\left(\Omega_{b}\right)$ is in units of government revenue per recipient household. Figure $4 \mathrm{~b}$ plots the mean markup on transfers from non-recipient states (NDI) to different sets of states $\Omega_{b}, E\left(M_{\omega} \mid \Omega_{b}\right)$, against mean counterfactual no-benefit annual earnings in those states. Markup is defined in equation (3) and calculated using PSID consumption excluding health care expenditures. Counterfactual no-benefit earnings are actual observed earnings for NDI states and are inferred from French and Song's (2014) estimates of the effects of USDP awards on earnings for DI states, as described in the text. In both panels, marker areas are proportional to population shares and monetary amounts are in 2016 dollars per year. Sample sizes: 313 M-DI, 438 L-DI, 248 M-NDI, 6259 L-NDI.

be nearly as valuable as benefits in more-severe states (M-DI).

That USDP mismatches are valuable rather than costly reflects strong selection into disability receipt conditional on health. On average, health is a strong indicator of the value of receiving disability benefits: Receiving disability benefits in the average more-severe state generates substantial surplus ( $\$ 5,000$ on average), whereas receiving disability benefits in the average less-severe state reduces surplus significantly ( $-\$ 16,800$ on average). But USDP mismatches are highly-selected subsets of their respective severity groups. The ex post states of the world in which an individual would receive disability benefits despite not having a more-severe condition (L-DI) have a large surplus from disability benefits $(\$ 7,700$ on average), while the ex post states of the world in which an individual would not receive disability benefits despite having a more-severe condition (M-NDI) have a negative surplus from disability benefits $(-\$ 2,200$ on average). That USDP mismatches are so favorably selected 
Table 1: Value of disability benefits in different states

\begin{tabular}{cccccc}
\hline & $\begin{array}{c}\text { Mean } \\
\text { markup } \\
\left(E\left(M_{\omega}\right)\right)\end{array}$ & $\begin{array}{c}\text { Counterfactual } \\
\text { no-benefit } \\
\text { earnings }(\$)\end{array}$ & $\begin{array}{c}\text { Surplus per } \\
\text { household }(\$) \\
\left(p\left(\Omega_{\tau}\right) s\right)\end{array}$ & $\begin{array}{c}\text { Surplus per } \\
\text { recipient HH }(\$) \\
\left(p\left(\Omega_{\tau}\right) s / p\left(\Omega_{b}\right)\right)\end{array}$ & $\begin{array}{c}\text { USDP value/value of } \\
\text { cost-equiv tax cuts } \\
((s+E A G) / E A G)\end{array}$ \\
\hline DI & 0.91 & 5,191 & 924 & 8,718 & 1.64 \\
M-DI & 0.95 & 3,557 & 488 & 9,858 & 1.73 \\
L-DI & 0.88 & 6,623 & 436 & 7,719 & 1.57 \\
NDI & 0.00 & 57,476 & $-15,930$ & $-17,819$ & 0.19 \\
M-NDI & 0.64 & 22,591 & -74 & $-2,203$ & 0.86 \\
L-NDI & -0.02 & 58,838 & $-15,856$ & $-18,429$ & 0.17 \\
All states & 0.10 & 51,932 & $-15,005$ & $-15,005$ & 0.29 \\
M & 0.82 & 11,252 & 414 & 4,982 & 1.34 \\
L & 0.03 & 55,620 & $-15,420$ & $-16,818$ & 0.23 \\
\hline
\end{tabular}

Notes: Table presents statistics (given by the column names) associated with receiving disability benefits in each of several sets of states of the world (row names). These states are those in which the household receives USDP benefits (DI), including when more-severe (M-DI) and less-severe (L-DI); those in which the household does not receive USDP benefits (NDI), including when more-severe (M-NDI) and less-severe (L-NDI); and all states (All states), including when more-severe (M) and less-severe (L). Markup is defined in equation (3) and calculated using PSID consumption excluding health care expenditures. Counterfactual no-benefit earnings are actual observed earnings for NDI states and are inferred from French and Song's (2014) estimates of the effects of USDP awards on earnings for DI states, as described in the text. Surplus $s$, defined in equation (6), is in units of government revenue per $\Omega_{\tau}$ state, so $p\left(\Omega_{\tau}\right) s$ is in units of government revenue per household and $p\left(\Omega_{\tau}\right) s / p\left(\Omega_{b}\right)$ is in units of government revenue per recipient household. Value relative to that of cost-equivalent tax cuts is derived in footnote 27. Monetary amounts are in 2016 dollars per year. Sample sizes: 313 M-DI, 438 L-DI, 248 M-NDI, 6259 L-NDI, 561 M, 6697 L.

on the value of receiving disability benefits is in keeping with the findings from the positive analysis that USDP mismatches are favorably selected on a wide variety of non-health factors.

Figure $4 \mathrm{~b}$ decomposes the selection on value into its two key determinants: marginal utility and counterfactual earnings. USDP recipients as a whole, and less-severe recipients (L-DI) in particular, are highly selected in terms of both marginal utility and counterfactual earnings, and so in terms of both the insurance benefit and distortion cost of receiving disability benefits. The markup on transfers from non-recipients to L-DI states is 0.88 , similar to that on transfers to M-DI states of 0.95. Mean counterfactual annual earnings in L-DI states is $\$ 6,600$, versus $\$ 3,600$ in M-DI states and $\$ 57,500$ in NDI states. Hence, the large surplus from benefits in L-DI states is driven not only by low consumption but also by low counterfactual earnings in those states. Strong selection on counterfactual earnings is crucial because of the earnings limit, which involves large private and fiscal externality costs in high-earning states. 
Selection into USDP receipt on both marginal utility and counterfactual earnings is so strong that awards to both M-DI and L-DI would generate positive surplus even if markups were just 25 percent of their estimated values (Appendix Table F4) or earnings responses were four times French and Song's (2014) estimates (Appendix Table F3).

The main conclusions that U.S. disability programs and their mismatches with respect to health are highly valuable hold not only overall, averaging across the different risk (education) types, but also for each risk type individually (see Appendix Table F1). They also hold under a wide range of assumptions about the key ingredients of the calculations, including the value and cost of the health insurance component (Appendix Table F2); earnings responses to receiving benefits (Appendix Table F3); risk aversion and state-dependence of utility (Appendix Table F4); the definition of severity (Appendix Table H1); and the definition of risk types (Appendix Table H2). Including the health insurance component tends to increase the surplus from both M-DI and L-DI benefits, somewhat more for M-DI than L-DI given their greater consumption of health care. As a result, the ratio of the per-recipient surplus of L-DI to M-DI benefits falls from its baseline value of 0.78 to $0.74-0.77$ when using our main assumptions about the health insurance component and to 0.54-0.71 when using extreme, ratio-minimizing assumptions across the board (see Appendix Section C for more details).

\subsection{Key drivers: Non-health risk and selective applications}

Non-health risk as a driver: About one-half of the value of USDP comes from insuring risks other than that of having a more-severe health condition. We investigate the connections between mismatches with respect to health and insurance against health and non-health risk with a decomposition analysis. For a given set of actual or hypothetical disability benefits in states $\Omega_{b} \subseteq \Omega_{\theta}$, decompose the benefit received in a particular state $\omega$ into the sum of (i) the mean benefit received in states in the same health category as $\omega, h_{\omega} \in\{\mathrm{L}, \mathrm{M}\}$, and (ii) a withinhealth category transfer from states in which the individual does not receive a benefit $\left(h=h_{\omega}\right.$ and $\left.\sim \Omega_{b}\right)$ to those in which they do $\left(h=h_{\omega}\right.$ and $\left.\Omega_{b}\right)$ :

$$
b_{\omega}=\underbrace{E\left(b \mid h=h_{\omega}\right)}_{\text {Health-contingent benefit }}+\underbrace{\left[b_{\omega}-E\left(b \mid h=h_{\omega}\right)\right]}_{\text {Within-health transfer }} .
$$


With this decomposition, the markup on transfers from all of $\theta$ 's states $\left(\Omega_{\theta}\right)$ to states $\Omega_{b} \subseteq \Omega_{\theta}$ can be decomposed as

$$
M_{\Omega}\left(\Omega_{b}\right)=\underbrace{\operatorname{Cov}_{h}\left[\frac{p\left(\Omega_{b} \mid h\right)}{p\left(\Omega_{b}\right)}, E(\widehat{\lambda} \mid h)\right]}_{\text {Insurance against health risk }}+\underbrace{E_{h}\left\{\frac{p\left(\Omega_{b} \mid h\right)}{p\left(\Omega_{b}\right)}\left[1-p\left(\Omega_{b} \mid h\right)\right]\left[E\left(\widehat{\lambda} \mid \Omega_{b}, h\right)-E\left(\widehat{\lambda} \mid \sim \Omega_{b}, h\right)\right]\right\}}_{\text {Insurance against non-health risk }},
$$

where $\widehat{\lambda} \equiv \frac{\lambda}{E(\lambda)}$ is marginal utility normalized to have unit mean in the population, and the conditioning on $\theta$ has been suppressed for notational ease. Details of the derivation are in Appendix Section E. ${ }^{34}$

The overall markup, $M_{\Omega}\left(\Omega_{b}\right)$, is the sum of two components. The "insurance against health risk" component, from the health-contingent benefit in equation (9), is from insuring the risk of having a more-severe health condition ("health risk"). The more concentrated are benefits in states in which the individual has a more-severe health condition (greater $p\left(\Omega_{b} \mid M\right)$ relative to $p\left(\Omega_{b} \mid L\right)$ ), the greater the insurance of health risk. This component is necessarily reduced by mismatches with respect to health, which by definition reduce the targeting of more-severe states. The "insurance against non-health risk" component, from the within-health transfer in equation (9), is from insuring "non-health risk," i.e., risk within health categories. ${ }^{35}$ The greater the marginal utility gap between recipient and non-recipient states within more-severe and less-severe states (i.e., greater $E\left(\hat{\lambda} \mid \Omega_{b}, h\right)-E\left(\widehat{\lambda} \mid \sim \Omega_{b}, h\right)$ ), the more valuable the insurance of non-health risk. This component is zero in the absence of mismatches. Mismatches make this component positive (negative) if appropriately-weighted selection into receiving disability benefits on marginal utility conditional on health is positive (negative).

Table 2 shows the results. The insurance that USDP provide against the risk of having a more-severe health condition is valuable, contributing 28 percentage points

\footnotetext{
${ }^{34}$ We calculate the markups on transfers within each education group and take the mean across education groups. These markups measure value in terms of income in all states of the world, $M_{\Omega}\left(\Omega_{b} ; \theta\right) \equiv \frac{E\left(\lambda \mid \theta, \Omega_{b}\right)-E(\lambda \mid \theta)}{E(\lambda \mid \theta)}$, rather than in terms of income in NDI states. We do this because it simplifies equation (10) and facilitates comparison across different groups of benefits. It also leads to somewhat smaller overall markups.

${ }^{35}$ We term this component "non-health risk" partly as a shorthand for "within-health category risk" and partly because the evidence suggests that much of this component is driven by factors that would not ordinarily be called "health," such as labor market shocks. But it is important to keep in mind that this component is technically within-health category risk, which both includes some health risk (e.g., some states in a given health category have higher out-of-pocket health spending than others) and excludes some non-health risk (to the extent that a risk is positively associated with having a more-severe health condition, part of it is included in the "health risk" component).
} 
Table 2: Decomposition of the markup on transfers into different states

\begin{tabular}{|c|c|c|c|c|c|c|}
\hline & \multirow{2}{*}{$\begin{array}{l}\text { Surplus per recip (\$) } \\
\quad\left(p\left(\Omega_{\tau}\right) s / p\left(\Omega_{b}\right)\right)\end{array}$} & \multirow{2}{*}{$\begin{array}{l}\text { Markup, } \\
E\left(M_{\Omega}\right)\end{array}$} & \multicolumn{2}{|c|}{ Contrib from insuring: } & \multicolumn{2}{|c|}{ Share from insuring: } \\
\hline & & & Health & Non-health & Health & Non-health \\
\hline DI & 8,718 & 0.75 & 0.28 & 0.48 & $37 \%$ & $63 \%$ \\
\hline M-DI & 9,858 & 0.78 & 0.66 & 0.12 & $85 \%$ & $15 \%$ \\
\hline L-DI & 7,719 & 0.73 & -0.06 & 0.79 & $-8 \%$ & $108 \%$ \\
\hline M-NDI & $-2,203$ & 0.48 & 0.66 & -0.18 & $136 \%$ & $-36 \%$ \\
\hline Health-DI & 4,982 & 0.66 & 0.66 & 0.00 & $100 \%$ & $0 \%$ \\
\hline Random-App-DI & $-6,143$ & 0.22 & 0.22 & 0.01 & $98 \%$ & $2 \%$ \\
\hline Earnings-Test-DI & 5,857 & 0.62 & 0.34 & 0.28 & $55 \%$ & $45 \%$ \\
\hline
\end{tabular}

Notes: Table presents social surplus per recipient, overall markup, and markup components and shares from insurance of health and non-health risk associated with disability benefits in each of several sets of states of the world, defined by the row. Contributions of insurance of health and non-health risk to overall markup are defined in equation (10). Shares of markup from insurance of each type of risk is the contribution of insurance of that type of risk to the overall markup as a share of the overall markup. The overall markup, $E\left(M_{\Omega}\right)$, is the across-risk group (education) average of the average within-risk group markup on transfers from all states (not just NDI states, as in the main analysis) to the states in the table row. Surplus $s$ (from equation (6)) is in units of government revenue per $\Omega_{\tau}$ state per year, so $p\left(\Omega_{\tau}\right) s / p\left(\Omega_{b}\right)$ is in units of government revenue per recipient per year. "Health-DI" is a hypothetical program that pays benefits if and only if the individual has a severe health condition. "Random-App-DI" is a hypothetical program whose award probabilities are a function of severity and age, as estimated by Low and Pistaferri (2015), and with no systematic selection into application, rather than the actual selective applications to DI. That Random-App-DI provides a small amount of insurance against non-health risk arises from the dependence of its award probabilities on age. "Earnings-Test-DI" is a hypothetical program whose award probabilities are a function of severity and age, as estimated by Low and Pistaferri (2015), and with no systematic selection into application (like Random-App-DI) except that the individual applies only in states in which counterfactual no-DI earnings are below two times the SSDI earnings test threshold. This is a simple model of the type of selection that an earnings test might produce. Sample sizes: 313 M-DI, 438 L-DI, 248 M-NDI, 561 Health-DI, 1060 Random-App-DI, 675 Earnings-Test-DI.

to the total markup. But the insurance that USDP provide against other risks contributes even more: 48 percentage points, $63 \%$ of the total markup. Even when we use additional health and disability measures to define finer health categories in equation (10), we still find that a majority of the insurance value of USDP comes from insuring risks within states with the same realizations of measured health. These results, which are in keeping with the earlier result that roughly half of the ex ante surplus from USDP comes from mismatches, suggest that a majority of the overall insurance value of USDP comes from insuring risks beyond that of having a more-severe health condition.

Mismatches with respect to health drive this insurance of non-health risk, albeit 
at the expense of necessarily reducing insurance against the risk of having a moresevere health condition. Compared to a hypothetical, infeasible program that would perfectly target states with more-severe health conditions ("Health-DI"), the acrosshealth component of USDP is less than one-half as large ( 0.28 for USDP versus 0.66 for Health-DI). Yet USDP more than makes up for their lesser insurance of the risk of having a more-severe health condition by providing highly valuable insurance against other risks. Insurance of other risks contributes 0.48 to the USDP markup (whereas by definition Health-DI does not insure risks within health categories), elevating the overall markup and surplus per recipient of USDP above those of Health-DI (0.75 versus 0.66 and $\$ 8,700$ versus $\$ 5,000$, respectively).

Although both types of mismatches insure non-health risk, the vast majority of such insurance comes from L-DI benefits. The "L-DI" row of the table decomposes the markup on transfers from all states to L-DI states, using the same approach used to decompose the overall markup (substituting "L-DI" for "DI" in equation (10)). L-DI benefits exacerbate health risk, by transferring from all states to lower-marginal utility L states, but provide highly valuable insurance against non-health risk, by transferring from L-NDI states to much higher-marginal utility L-DI states. The insurance against non-health risk provided by L-DI benefits accounts for over half of the overall USDP markup and $85 \%$ of the "insurance of non-health risk" markup component.

\section{Selective applications as a driver: the insurance of non-health risk and overall value of USDP are driven primarily by strong selection into appli- cation (as opposed to selective awards given applications). We investigate} the importance of selective applications by comparing USDP to a hypothetical disability program with no systematic selection into application ("Random-App-DI"). ${ }^{36}$ The results, shown in the second-to-last row of Table 2, suggest that selection into application plays a crucial role in driving the overall value of USDP. Whereas USDP generate $\$ 8,700$ per recipient worth of annual surplus, Random-App-DI would generate negative surplus $(-\$ 6,100)$ - i.e., individuals would prefer cost-equivalent tax cuts

\footnotetext{
${ }^{36}$ To simulate the distribution of benefits under Random-App-DI, we use Low and Pistaferri's (2015) estimates of USDP award success probabilities, which are a function of an applicant's work limitation status and age, and assume that each applicant applies for Random-App-DI up to two times. Because actual USDP awards account for factors beyond those in Low and Pistaferri's (2015) model (e.g., through the vocational grid), this analysis does not isolate the effect of selective applications alone but the combined effect with richer award decisions as well.
} 
to Random-App-DI. The difference is driven almost entirely by USDP insuring risks beyond that of having a more-severe health condition. The USDP markup exceeds the Random-App-DI markup by 53 percentage points, 47 percentage points (89\%) of which are from within-health transfers. Selection into application is responsible for the vast majority of the insurance against non-health risk provided by USDP, which itself is highly important to the overall value of USDP. Of course, selective award decisions likely play a major role in shaping selection into application, so the importance of selection into application does not imply that selective award decisions are unimportant. Rather, it means that the net effect of USDP award decisions and other features - including restrictions on applicants and recipients, awareness, hassle costs, and stigma - is strongly favorable selection into application that greatly increases the value of USDP.

Which of these features in particular explains the strong, value-enhancing selection into application for disability benefits? Unfortunately there is little in the way of compelling variation that would facilitate a direct empirical investigation of this important issue. But indirect evidence suggests that the stringent earnings limit could potentially play a key role. We simulate the effects of the type of selection that an earnings limit might produce by considering a hypothetical program ("Earnings-TestDI") that is equivalent to Random-App-DI except that the individual applies only in states in which counterfactual no-benefit earnings are below two times the earnings limit. ${ }^{37}$ The last row of Table 2 shows the results. Whereas Random-App-DI would be quite costly (surplus per recipient of $-\$ 6,100$ ), Earnings-Test-DI would be quite valuable (surplus per recipient of $\$ 5,900$ ). The difference arises because the assumed self-selection out of application by individuals in states with high counterfactual nobenefit earnings avoids the high-cost, low-value benefits in those states, and it greatly increases the extent to which disability benefits insure non-health risk. To be clear,

\footnotetext{
${ }^{37}$ The results are qualitatively similar if the threshold for applying is one or three times the earnings limit instead. As with Random-App-DI, we report the results of a simulation in which individuals rejected once re-apply a second time, but the results are similar if individuals apply only once or up to three times. This simple model of selection may understate the screening effects of the earnings limit by ignoring dynamics. Given the substantial fixed costs to individuals with nonnegligible earning opportunities of applying for disability benefits (especially the long application process during which earnings must be low), the earnings limit likely deters applications even in many states in which current no-benefit earnings are low but anticipated future earnings are higher. Strong selection into application on the basis of future no-benefit earnings is consistent with French and Song's (2014) finding that rejected applicants on the margin of program entry have low earnings throughout the ten-year period following their application.
} 
these results provide suggestive evidence on the potential screening effects of an earnings limit alone and so do not isolate the marginal effect of the earnings limit on top of the many other tags and screens of U.S. disability programs.

\subsection{Policy implications}

Together, the findings from the positive and normative analyses paint a picture of U.S. disability programs that target well on the key determinants of the value of receiving disability benefits. Subject to the caveats that we have discussed, our results have important implications for some of the biggest questions in the debate over these programs.

Is the provision of benefits to individuals with less-severe conditions diluting the value of U.S. disability programs? Our results suggest that the benefits received by less-severe recipients are not diluting the value of USDP, at least not in terms of insurance and welfare, but rather providing highly valuable insurance against a variety of major risks. To the extent that more-severe recipients are considered deserving of disability benefits on the basis of the ex ante value of such benefits, less-severe recipients appear nearly as deserving. To be sure, our results do not imply that USDP should reduce efforts to target individuals who have severe health conditions or increase efforts to target based on non-health factors. The value of such changes to tags or screens depends on the induced application responses, the evidence on which is unfortunately sparse. It could be that efforts to target individuals with severe health conditions are an important driver of the strong selection into application on non-health risk that we find to be so crucial to the value of USDP.

Would proposed reforms to U.S. disability programs increase or decrease social welfare? We quantify the value of proposed reforms to U.S. disability programs, with details in Appendix Section D and results in Appendix Table F5. The results suggest that proposed reforms to decrease benefit levels, allowance rates, or awards to individuals with less-severe health conditions would each significantly decrease social surplus. Even a costless elimination of awards to individuals with lesssevere health conditions would decrease social surplus. That is not to say, however, that increasing eligibility would increase social surplus, since we find that extreme 
selectivity is crucial to the value of USDP. ${ }^{38}$ Of course, a distinct question, and one that this paper is not equipped to answer, is whether U.S. disability programs should be expanded. Such a normative judgment depends on considerations beyond insurance and welfare, including non-welfarist considerations about the appropriate role of disability programs or about the extent to which different individuals or states are deserving of benefits. Our results suggest that such considerations would have to be fairly strong, in terms of their effects on generalized social marginal welfare weights (Saez and Stantcheva, 2016), in order to overturn our main conclusions. To overturn the conclusion that disability benefits to less-severe recipients are valuable would require that each dollar of such benefits be viewed as being worth less than 65 cents. To overturn the conclusion that disability benefits as a whole are valuable would require that each dollar of benefits to less-severe recipients be viewed as being worth less than 25 cents.

Are disability programs the best way to insure non-health risk? Our finding that U.S. disability programs provide cost-effective insurance against non-health risk does not necessarily mean that they are the most cost-effective way to do so. The earnings limit in particular makes disability benefits a costly way to insure risks that do not involve prolonged low earnings prospects. For individuals with high earnings capacity, insuring them through other means - perhaps by expanding UI or creating a new wage insurance program - could be valuable. But the available evidence suggests that the vast majority of disability recipients, including those with less-severe health conditions, would earn little even if not receiving disability benefits. ${ }^{39}$ Moreover, expansions of alternative programs would have efficiency costs of their own and may

\footnotetext{
${ }^{38} \mathrm{An}$ additional consideration for the effects of disability insurance on social welfare is possible redistribution value. Throughout the paper, we have focused on efficiency - insurance of risk within risk types, setting aside any redistribution across risk types - since redistribution across risk types can be accomplished by the income tax and transfer system. But without offsetting changes in other policies, expanding USDP would redistribute from higher- to lower-ability groups, since lowerability groups both are more likely to receive disability benefits and pay lower absolute amounts of the payroll taxes that fund USDP. Such redistribution would increase the overall social welfare value of USDP under social welfare functions that value redistribution more than the income tax and transfer implicitly does. We find that accounting for redistribution increases the value of USDP to someone behind the veil by about $30 \%$.

${ }^{39}$ Only about $20-30 \%$ of SSDI recipients on the margin of allowance would earn at least the "substantial gainful activity" threshold (about \$16,000 in 2021) if they did not receive SSDI (Maestas, Mullen and Strand, 2013; French and Song, 2014). This share would presumably be lower for inframarginal recipients and at higher earnings thresholds, though we are unaware of direct evidence on either.
} 
lack the advantageous targeting properties that we find for USDP. ${ }^{40}$

Setting aside overall welfare effects, how might changes in other programs affect the value of U.S. disability programs? We provide suggestive evidence by estimating how the value of disability benefits to less-severe individuals changes as certain subsets of less-severe individuals are excluded. If individuals with less-severe conditions who received UI prior to receiving disability benefits did not switch to disabilityfor example, due to a major UI extension - the estimated surplus from L-DI benefits would fall by $33 \%$. Excluding individuals with less-severe conditions who experienced an observable job loss prior to receiving disability benefits but did not receive UI - as might occur under a major expansion of UI eligibility - would reduce the estimated surplus from L-DI benefits by an additional 14 percentage points. While only suggestive, these results indicate that USDP might continue to provide substantial insurance against non-health risk even if there were large expansions of programs designed to insure non-health risk. ${ }^{41}$

\section{Conclusion}

The public debate over disability insurance has centered on concerns about individuals with less-severe health conditions receiving benefits. In this paper, we go beyond health risk alone to quantify the insurance provided by U.S. disability programs against all risks, non-health as well as health. We find that not only are these programs highly valuable, but their mismatches with respect to health, including benefits to individuals with less-severe health conditions, actually increase their value.

\footnotetext{
${ }^{40}$ Acknowledging the substantial uncertainty about the fiscal externality costs of changes in USDP, our analysis of potential changes in USDP policy, reported in Appendix Table F5, suggests that USDP provide more cost-effective insurance than UI does. Our estimates of the ex ante MVPFs of each of three key dimensions of disability policy - paying benefits to individuals with less-severe conditions, changing benefit levels, and changing the award threshold - are about 1.42. This significantly exceeds Hendren and Sprung-Keyser's (2019) estimates of the ex ante MVPF of changes in UI (main estimate of 0.61 with range $0.53-0.74$ ). The higher MVPFs of changes in USDP arise from reinforcing effects of higher insurance value markups (0.88-0.91 for USDP versus 0.20 for UI) and lower fiscal externality costs (0.34 for USDP versus 0.95 for UI).

${ }^{41}$ Of course, the changes in other programs required to have such an impact on disability enrollment might be large given the long-lasting nature of disability receipt, the persistently low earnings among individuals who apply for disability benefits, and the evidence that changes in UI have little effect on disability receipt (Mueller, Rothstein and Von Wachter, 2016). Note also that expansions of other programs would not necessarily decrease the value of USDP. They might even increase it by improving USDP targeting further still, as Low and Pistaferri (2015) find in their structural model.
} 
This is because disability recipients with less-severe conditions are a highly selected group: Compared to non-recipients, less-severe recipients are more likely to have experienced adverse non-health events, are less likely to have the resources to insure those events, and are more likely to have low earnings even if not for receiving disability benefits. In fact, recipients with less-severe conditions are so highly selected that they look similar to or worse off than recipients with more-severe conditions on these dimensions.

As a result of this strong selection, disability benefits to both more-severe and lesssevere recipients produce insurance value substantially greater than distortion cost, and so are significantly more valuable ex ante than cost-equivalent tax cuts. Our results suggest that about one-half of the value of U.S. disability programs comes from insuring non-health risk. For this reason, reforms to increase the emphasis of these programs on health could significantly reduce their ex ante value.

The importance of non-health risk for the value of U.S. disability programs may be just one example of a broader phenomenon. No program exists in a vacuum: Its effects reflect the diversity of risks in the economy, how well insured those risks are by other programs and institutions, and how its tags and screens select on those risks. We find that U.S. disability programs insure risks well beyond health, and that this "incidental" role is central to their overall value. Other programs might be similar in having their costs and benefits driven in large part by factors outside of their core aims. The extent to which they do is an empirical question, one that future research could investigate using similar methods. 


\section{References}

Alatas, Vivi, Ririn Purnamasari, Matthew Wai-Poi, Abhijit Banerjee, Benjamin A Olken, and Rema Hanna. 2016. "Self-Targeting: Evidence from A Field Experiment in Indonesia." Journal of Political Economy, 124(2): 371-427.

Autor, David H, and Mark G Duggan. 2003. "The Rise in the Disability Rolls and the Decline in Unemployment." The Quarterly Journal of Economics, 118(1): 157-206.

Autor, David H., and Mark G. Duggan. 2006. "The Growth in the Social Security Disability Rolls: A Fiscal Crisis Unfolding." Journal of Economic Perspectives, 20(3): 71-96.

Benitez-Silva, Hugo, Moshe Buchinsky, and John Rust. 2004. "How Large Are the Classification Errors in the Social Security Disability Award Process?" National Bureau of Economic Research.

Bhargava, Saurabh, and Dayanand Manoli. 2015. "Psychological Frictions and the Incomplete Take-Up of Social Benefits: Evidence from An IRS Field Experiment." American Economic Review, 105(11): 3489-3529.

Black, Dan, Kermit Daniel, and Seth Sanders. 2002. "The Impact of Economic Conditions on Participation in Disability Programs: Evidence from the Coal Boom and Bust." American Economic Review, 92(1): 27-50.

Bound, John, Julie Berry Cullen, Austin Nichols, and Lucie Schmidt. 2004. "The Welfare Implications of Increasing Disability Insurance Benefit Generosity." Journal of Public Economics, 88(12): 2487-2514.

Brown, Jeffrey R, Gopi Shah Goda, and Kathleen McGarry. 2016. "Heterogeneity in State-Dependent Utility: Evidence from Strategic Surveys." Economic Inquiry, 54(2): 847-861.

Cabral, Marika, and Mark R Cullen. 2019. "Estimating the Value of Public Insurance Using Complementary Private Insurance." American Economic Journal: Economic Policy, 11(3): 88-129. 
Chandra, Amitabh, and Andrew A Samwick. 2009. "Disability Risk and the Value of Disability Insurance." In Health at Older Ages: The Causes and Consequences of Declining Disability among the Elderly. 295-336. University of Chicago Press.

Charles, Kerwin Kofi, Yiming Li, and Melvin Stephens Jr. 2018. "Disability Benefit Take-Up and Local Labor Market Conditions." Review of Economics and Statistics, 100(3): 416-423.

Chetty, Raj. 2006. "A General Formula for the Optimal Level of Social Insurance." Journal of Public Economics, 90(10-11): 1879-1901.

Chetty, Raj, and Adam Looney. 2006. "Consumption Smoothing and the Welfare Consequences of Social Insurance in Developing Economies." Journal of Public Economics, 90(12): 2351-2356.

Currie, Janet. 2006. "The Take-Up of Social Benefits." In Public Policy and the Income Distribution., ed. Alan J. Auerbach, David Card and John M. Quigley, 80-148. New York, NY: Russell Sage Foundation Publications.

Deshpande, Manasi, and Yue Li. 2019. "Who is Screened Out? Application Costs and the Targeting of Disability programs." American Economic Journal: Economic Policy, 11(4): 213-48.

Deshpande, Manasi, Tal Gross, and Yalun Su. 2019. "Disability and Distress: The Effect of Disability Programs on Financial Outcomes." National Bureau of Economic Research.

Diamond, Peter, and Eytan Sheshinski. 1995. "Economic Aspects of Optimal Disability Benefits." Journal of Public Economics, 57(1): 1-23.

Finkelstein, Amy, and Matthew J Notowidigdo. 2019. "Take-Up and Targeting: Experimental Evidence from SNAP." The Quarterly Journal of Economics, 134(3): 1505-1556.

Finkelstein, Amy, Erzo F. P. Luttmer, and Matthew J. Notowidigdo. 2013. "What Good Is Wealth Without Health? The Effect of Health on the Marginal Utility of Consumption." Journal of the European Economic Association, 11: 221258. 
Finkelstein, Amy, Nathaniel Hendren, and Erzo F. P. Luttmer. 2019. "The Value of Medicaid: Interpreting Results from the Oregon Health Insurance Experiment." Journal of Political Economy, 127(6): 2836-2874.

Finkelstein, Amy, Neale Mahoney, and Matthew J. Notowidigdo. 2018. "What Does (Formal) Health Insurance Do, and for Whom?" Annual Review of Economics, 10(1): 261-286.

French, Eric, and Jae Song. 2014. "The Effect of Disability Insurance Receipt on Labor Supply." American Economic Journal: Economic Policy, 6(2): 291-337.

Gelber, Alexander, Timothy Moore, and Alexander Strand. 2018. "Disability Insurance Income Saves Lives." Unpublished Manuscript.

Greszler, Rachel, Robert E Moffit, and Nina Owcharenko Schaefer. 2019. "Social Security and Health Care Entitlement Reform." Blueprint for Balance: A Federal Budget for Fiscal Year 2020.

Hendren, Nathaniel. 2020. "Measuring Economic Efficiency Using InverseOptimum Weights." Journal of Public Economics, 187: 104198.

Hendren, Nathaniel, and Ben Sprung-Keyser. 2019. "A Unified Welfare Analysis of Government Policies." National Bureau of Economic Research NBER Working Papers 26144.

Homonoff, Tatiana, and Jason Somerville. 2020. "Program Recertification Costs: Evidence from SNAP." National Bureau of Economic Research.

Jacobson, Louis S, Robert J LaLonde, and Daniel G Sullivan. 1993. "Earnings Losses of Displaced Workers." The American Economic Review, 685-709.

Jones, Maggie R., and James P. Ziliak. 2019. "The Antipoverty Impact of the EITC: New Estimates from Survey and Administrative Tax Records." Center for Economic Studies, U.S. Census Bureau Working Papers 19-14.

Kleven, Henrik Jacobsen, and Wojciech Kopczuk. 2011. "Transfer Program Complexity and the Take-Up of Social Benefits." American Economic Journal: Economic Policy, 3(1): 54-90. 
Lieber, Ethan MJ, and Lee M Lockwood. 2019. "Targeting with In-Kind Transfers: Evidence from Medicaid Home Care." American Economic Review, 109(4): 1461-85.

Liebman, Jeffrey B. 2015. "Understanding the Increase in Disability Insurance Benefit Receipt in the United States." Journal of Economic Perspectives, 29(2): 123-50.

Lillard, Lee A, and Yoram Weiss. 1997. "Uncertain Health and Survival: Effects on End-of-Life Consumption." Journal of Business 83 Economic Statistics, 15(2): 254-268.

Livermore, Gina, David Stapleton, Henry Claypool, et al. 2009. Health insurance and health care access before and after SSDI entry. Commonwealth Fund.

Low, Hamish, and Luigi Pistaferri. 2015. "Disability Insurance and the Dynamics of the Incentive Insurance Trade-off." American Economic Review, 105(10): 29863029 .

Maestas, Nicole, Kathleen J. Mullen, and Alexander Strand. 2013. "Does Disability Insurance Receipt Discourage Work? Using Examiner Assignment to Estimate Causal Effects of SSDI Receipt." American Economic Review, 103(5): 17971829.

McCrery, Jim, and Earl Pomeroy. 2016. "SSDI Solutions: Ideas to Strengthen the Social Security Disability Insurance Program."

Meyer, Bruce D, and Wallace KC Mok. 2019. "Disability, Earnings, Income and Consumption." Journal of Public Economics, 171: 51-69.

Meyer, Bruce D, Wallace KC Mok, and James X Sullivan. 2015. "Household Surveys in Crisis." Journal of Economic Perspectives, 29(4): 199-226.

Mueller, Andreas I, Jesse Rothstein, and Till M Von Wachter. 2016. "Unemployment Insurance and Disability Insurance in the Great Recession." Journal of Labor Economics, 34(S1): S445-S475.

Parsons, Donald O. 1991. "The Health and Earnings of Rejected Disability Insurance Applicants: Comment." The American Economic Review, 81(5): 1419-1426. 
Rege, Mari, Kjetil Telle, and Mark Votruba. 2009. "The Effect of Plant Downsizing on Disability Pension Utilization." Journal of the European Economic Association, 7(4): 754-785.

Riley, Gerald F. 2006. "Health insurance and access to care among Social Security Disability Insurance beneficiaries during the Medicare waiting period." INQUIRY: The Journal of Health Care Organization, Provision, and Financing, 43(3): 222230.

Saez, Emmanuel, and Stefanie Stantcheva. 2016. "Generalized Social Marginal Welfare Weights for Optimal Tax Theory." American Economic Review, 106(1): 2445.

Short, Pamela Farley, and France Marie Weaver. 2008. "Transitioning To Medicare Before Age Sixty-Five: The question is whether to eliminate, partially or entirely, the two-year waiting period for Medicare." Health Affairs, 27(Suppl1): w175-w184.

Sullivan, Daniel, and Till Von Wachter. 2009. "Job Displacement and Mortality: An Analysis Using Administrative Data." The Quarterly Journal of Economics, 124(3): 1265-1306.

United States Office of Management and Budget. 2020. Fiscal Year 2021: A Budget for America's Future. U.S. Government Publishing Office.

Von Wachter, Till, Jae Song, and Joyce Manchester. 2011. "Trends in Employment and Earnings of Allowed and Rejected Applicants to the Social Security Disability Insurance Program." American Economic Review, 101(7): 3308-29. 